\title{
La medición de la ganancia mercantil en el Río de la Plata colonial: el caso de Diego de Agüero y Compañía (Río de la Plata, 1770-1820)
}

\author{
por \\ Mariano Martín Schlez \\ Universidad Nacional del Sur / CONICET \\ mmschlez@hotmail.com
}

El artículo reconstruye las actividades mercantiles de uno de los principales comerciantes del Virreinato del Río de la Plata, el español Diego de Agüero, a lo largo de toda su actuación mercantil (1770-1820), con el objetivo de medir y analizar el origen de sus ganancias, así como ponderar la magnitud de su patrimonio. Para ello recurre a documentación serial (registros de navios y protocolos notariales) y privada (correspondencia y documentación contable), proveniente de repositorios de Argentina, Uruguay, Brasil, Bolivia y España. De esta manera se prueba, para el caso analizado, la inexistencia de una tasa de ganancia, en el sentido contemporáneo del término, y la enorme disparidad de resultados en sus operaciones mercantiles, las que podian realizarse gracias a la existencia de un sistema social específico, que resistía el avance de la competencia mediante mecanismos extraeconómicos.

Palabras Clave: Imperio español; comercio colonial; comerciantes; tasa de ganancia.

La estructura económica de la Carrera no quedará verdaderamente esclarecida hasta que no la dejemos caer sobre los grupos sociales que la sustentaban y la ajustemos en sus goznes. La razón de lo segundo radica, a su vez, en que el tema se nos derrama, por así decirlo, entre las manos, faltos, sobre todo, de estudios e investigaciones referidas a individuos o dinastías comerciales concretas, que nos permitieran acercarnos a la actuación personal del comerciante y su dimensión vital y profesional (aprendizaje, tipificación de sus actividades, estrategia de sus negocios, monto de sus fortunas, enlaces familiares, enclaves en la administración, etc.). Mucha responsabilidad de ello recae en la ausencia 
de documentación privada (archivos familiares desaparecidos o inaccesibles al investigador) aunque sin olvidar también la dificultad del estudio de la pública, es decir, la notarial.

Antonio García Baquero-González

Los comerciantes de larga distancia fueron uno de los protagonistas principales de la historia moderna, algo que la historiografía reconoció con una notable producción dedicada a su análisis, que mantiene su vigencia hasta nuestros días ${ }^{1}$. Su estudio fue abordado desde perspectivas teórico-metodológicas diversas, atendiendo a una variada gama de problemas políticos, económicos, sociales y culturales. No obstante, el predominio de trabajos que apelaron a la categoría de redes sociales y familiares, relegó los intentos por dilucidar la naturaleza social de los mercaderes coloniales ${ }^{2}$. Y aunque el conocimiento de los clanes mercantiles nos permitió una mirada más atenta de una serie de procesos sociales, una explicación de los límites y potencialidades que poseía la carrera de indias nos obliga a retomar el debate en torno a las clases (grupos, fracciones y capas) sociales que posibilitaron el comercio colonial, y a los mecanismos económicos puestos en práctica para su desarrollo ${ }^{3}$.

En esta oportunidad nos dedicaremos al que consideramos el nudo de dicha perspectiva, a saber, la descripción, análisis y medición de las ganancias obtenidas por los comerciantes coloniales en sus negocios. Tarea que realizaremos a través del estudio del caso del comerciante mayorista español Diego de Agüero, a lo largo de todo el período de su actuación mercantil (1770-1820) en el Río de la Plata (Buenos Aires y Montevideo). Como veremos oportunamente, se trata de un observable significativo en tanto nos permitirá aproximarnos a los fundamentos económicos de la fracción de comerciantes rioplatenses que se opuso (corporativamente, primero, y política y militarmente después) a la revolución de independencia de $1810^{4}$.

Entendemos que el problema esconde dos aristas: por un lado, la ponderación concreta de los porcentajes de ganancia obtenidos y los volúmenes de

${ }^{1}$ Silva, 2010. Herrero, 2013. Lobato y Oliva, 2013.

${ }^{2}$ Una compilación que expresa la diversidad de perspectivas y aportes en Crespo Solana, 2010. Entre los principales exponentes de los estudios de redes se encuentran los clásicos de Socolow, 1991 y Moutoukias, 1992. Sobre el análisis de la naturaleza social de los comerciantes, véase Schlez, 2010.

${ }^{3}$ García-Baquero González, 1989; 1992.

${ }^{4}$ Schlez, 2012. 
riqueza acumulados (aspecto cuantitativo) ${ }^{5}$; y, por el otro, las condiciones sociales que permitían desplegar una serie de mecanismos específicos empleados para obtener dicha masa de valor (aspecto cualitativo). Ellas nos permitirán adentrarnos en el universo social del comercio colonial y evaluar su dinámica, así como los fundamentos objetivos y subjetivos en los que se asentaba.

EL ORIGEN Y MEDICIÓN DE LA GANANCIA MERCANTIL EN LA CARRERA DE INDIAS

La cuestión del origen de la ganancia en el comercio colonial español no es nueva, y encontramos explicaciones, incluso, entre los protagonistas del proceso que analizamos. Es ya conocido el balance del primer secretario del Consulado de Buenos Aires (1794), Manuel Belgrano, quien criticó a los mercaderes españoles debido a que «nada sabían más que su comercio monopolista, a saber: comprar por cuatro para vender por ocho, con toda seguridad ${ }^{6}$. Tan acertado fue su planteo que uno de los estudios pioneros sobre el tema también concluyó, luego de un detallado análisis del capital mercantil catalán, que el objetivo de los comerciantes coloniales era comprar barato para vender más caro. Fue así que, siguiendo las hipótesis de Karl Marx, Pierre Vilar señaló el origen divergente de la ganancia en el feudalismo y en el capitalismo: mientras que en el primer caso, era resultado de usuras, acopios, monopolios, especulaciones sobre la escasez y desequilibrios entre mercados lejanos y desconocidos entre sí, en el segundo se trataba de la «retribución regularizada de un simple servicio distributivo» ${ }^{7}$. En este sentido, AntonioMiguel Bernal demostró que «la especulación y el riesgo marcaban la tasa de beneficio» del comercio español con América desde 1492, constituyéndose ambos elementos en determinantes a la hora de evaluar los mecanismos constitutivos de la ganancia ${ }^{8}$.

Desde entonces, fueron numerosos los estudios dedicados a dilucidar los mecanismos puestos en práctica por los comerciantes para obtener su lucro y acrecentar su patrimonio. Mientras que un conjunto de historiadores señaló el predominio del capital mercantil sobre el productivo, también se probó que el otorgamiento de crédito (en dinero o especie), la escasez monetaria y la disparidad de precios se encontraban entre los elementos que explicaban el

\footnotetext{
5 Vila Vilar, 2001. Gutiérrez Lorenzo, 1988.

${ }^{6}$ Belgrano, 1960.

7 Vilar, 1988: 12. El marco teórico de su estudio en Marx, 2000.

${ }^{8}$ Bernal, 1992: 100.
} 
origen de la ganancia comercial ${ }^{9}$. Quedó claro, asimismo, que el desarrollo de actividades vinculadas al tráfico, aunque no estrictamente comerciales, como el flete de mercancías y el otorgamiento de seguros, también coadyuvaron al incremento del beneficio. En este sentido, estudios que dieron cuenta de la naturaleza social del beneficio obtenido por el capital mercantil mostraron no sólo el desarrollo de fracciones mercantiles divergentes, sino incluso antagónicas ${ }^{10}$. En este punto, fue pertinente el aporte de los especialistas en la carrera de indias, en tanto demostraron la centralidad del vínculo colonial entre España y América, y el carácter monopólico de su comercio, como elemento central para la obtención de un beneficio extraordinario ${ }^{11}$.

No obstante este desarrollo, aún debemos profundizar en el conocimiento de los orígenes, mecanismos, tasas y volúmenes de ganancia de los comerciantes radicados en América, desconocimiento que puede extenderse al conjunto del imperio español ${ }^{12}$. En primer lugar, aún se encuentra sin dilucidar si ella provenía mayoritariamente de su actuación en tanto comisionistas o si tenía su origen en actividades por cuenta propia. Asimismo, también debe evaluarse si se trataba del resultado de inversiones productivas (minas, haciendas, textiles) o si provenían, estrictamente, de actividades mercantiles ${ }^{13}$.

Quienes se dedicaron a estos problemas no han arribado aún a acuerdos consolidados. Por un lado, se difiere no sólo respecto del monto obtenido por los comerciantes en sus negociaciones, sino también sobre su regularidad, discutiéndose la existencia de una tasa de ganancia en mercados pre-capitalistas. Con respecto al primer problema, mientras que una serie de trabajos sostiene la existencia de enormes beneficios, con tasas de hasta el $400 \%$, otros aseguran que el porcentaje de utilidad apenas soportaba los elevados costos del

9 Véase Dalla Corte, 2000 para un estudio de caso que atiende a los mecanismos mercantiles de uno de los principales comerciantes rioplatenses. Los estudios de Carmagnani (1975), Garavaglia (1983) y Kriedte (1987) fueron pioneros en demostrar el predominio del capital mercantil sobre el productivo. Las investigaciones de Greenow (1983), Chiaramonte (1984), Kicza (1986) y Bernal (1992) aportaron elementos centrales para comprender los orígenes de la ganancia mercantil colonial.

${ }_{10}$ Ruiz Rivera (1983) analiza empresas dedicadas al flete y Tortella (2011) atiende el papel de los seguros. Un estudio que considera los antagonismos sociales que recorren al capital mercantil en Astarita (1992).

${ }^{11}$ Laclau, Cardoso, Ciafardini, Garavaglia y Sempat, 1989. Laviana Cuetos, 2006.

12 Bernal, 1992: 178.

13 Martínez Shaw (1981) ha probado que existen fracciones de la burguesía catalana que poseen un rasgo distintivo, al dedicarse no sólo a actividades mercantiles, sino también a la producción textil, lo que consideramos un elemento central a la hora de conceptualizar al capital mercantil. 
tráfico de Indias ${ }^{14}$. Por su parte, aunque un estudio de caso señala márgenes que rondaban el $70 \%$, dando por sentado algún tipo de regularidad en ello, otro da cuenta de la variabilidad de las ganancias obtenidas y de márgenes mucho más discretos (de entre el $10 \%$ y el $30 \%$, de acuerdo a las condiciones del mercado ${ }^{15}$. Naturalmente, los escasos trabajos dedicados al tema tuvieron en cuenta las diferentes coyunturas del comercio colonial español: mientras que durante los primeros años de la carrera de indias parece plausible la obtención de enormes ganancias, es evidente que no puede señalarse lo mismo para períodos posteriores, en los que se agudizó la competencia ${ }^{16}$.

Paralelamente, investigaciones más exhaustivas evaluaron los mecanismos concretos, económicos y extraeconómicos, que permitían a los comerciantes obtener su utilidad. Retomando los estudios clásicos que dieron cuenta del lugar de la circulación y escasez de moneda, se analizaron los patrones de comportamiento e inversión, la apropiación y sentido de las riquezas monetarias, la diferencia entre crédito y fiado y la función de las vinculaciones con el poder político de los comerciantes, a partir de estudios de caso ${ }^{17}$. Los resultados refutan la idea de una tasa de ganancia regular en el comercio, en particular, y en otro tipo de negocios, en general, mostrando la existencia de diferentes porcentajes de beneficio en las diversas actividades desplegadas ${ }^{18}$.

${ }^{14}$ Entre los primeros se encuentra Bernal (1992: 178); entre los segundos, Brading, 1975.

15 Mientras que del trabajo de Socolow (1975) se desprende cierta regularidad en la tasa de beneficio, la investigación de Suárez Argüello (2003) señala lo contrario.

${ }_{16}$ Para los inicios de la carrera de indias, véase Otte, 1968. Sobre su derrotero en el siglo XVIII, Bernal, 1992: 419.

17 Las primeras aproximaciones al tema en Romano (1965), Tándeter y Wachtel (1975) y un estudio de caso particularmente significativo en Gelman (1987; 1989; 1990; 1996).

${ }^{18}$ El comerciante y hacendado Domingo Belgrano Pérez habría obtenido un 5\% de interés anual sobre el crédito en efectivo otorgado; un 7,5\% anual por la renta de sus propiedades urbanas; un 9 o $10 \%$ de ganancia por su actividad como comisionista de casas comerciales gaditanas; un 19,3\%, en un lapso de dos años y medio, por una tienda que posee en Buenos Aires; un $58 \%$ de beneficio mínimo por una compañía para vender efectos en Corrientes; un $14,7 \%$, en dos años, por otra compañía para vender efectos en Salta $(7,3 \%$ para Belgrano, por división de utilidades); un 32\%, por la venta de yerba de Asunción en Buenos Aires; un $92 \%$, en dos años, por la venta de esclavos de Brasil en Lima; un $65 \%$, en un año, por la venta de cueros rioplatenses en Cádiz; un 77,7\%, en poco más de un año, por la venta de lana de vicuña de Jujuy en Cádiz; y un 333,3\% de beneficio mínimo por el arriendo de la cuatropea en la Banda Oriental. Asimismo, el estudio de Bernal prueba la enorme variabilidad de ganancias a lo largo de los tres siglos de comercio colonial español, con tasas de ganancia que iban desde el 7\% (comisión estipulada para los factores), hasta porcentajes de más del $100 \%$ de beneficio neto, aún en un período relativamente tardío, como 1749 . Véase Gelman, 1996: 128-134 y Bernal, 1992: 177 y 372. 
Lamentablemente, las conclusiones no dejan de ser parciales, en tanto aún debemos lidiar con dificultades en torno a la documentación, dado que la falta de cuentas de ventas y gastos, o recibos y documentos contables que especifiquen cada una de las variables (costo de los efectos, precio de compra y venta, costos del transporte, seguros y almacenaje, etc.), obliga a los investigadores a apelar a fuentes alternativas, fundamentalmente seriales (protocolos notariales o registros de navíos) y a datos historiográficos para llevar adelante sus cálculos, lo que siempre acrecienta las posibilidades de distorsiones. Por ejemplo, Jorge Gelman desconoce los precios concretos de las operaciones llevadas adelante por su objeto de estudio, Domingo Belgrano Pérez, por lo que reemplaza dicho faltante con series de precios construidas por la historiografía.

Dicho recurso, aunque válido, presenta dos problemas: por un lado, la bibliografía no siempre explicita la moneda en que construye sus datos, dificultando su utilización; y por el otro, teniendo en cuenta la importante divergencia de precios de la economía colonial, una metodología que apela a datos que no pertenecen estrictamente a la operación específicamente analizada debe concluir en que el cálculo de la ganancia no puede considerarse definitivo. Problema reconocido hace ya varias décadas, planteando la historiografía la necesidad de avanzar en estudios de caso que apelen a documentación contable privada para resolverlo ${ }^{19}$.

\section{OBJeTivo, METodología y FUENTES}

Nuestro balance del derrotero historiográfico nos condujo a tomar una serie de decisiones de carácter teórico-metodológico. En primer lugar, realizar un estudio de caso que sea particularmente significativo y del que se haya conservado la documentación privada para su análisis. En segundo, que el

19 Gelman (1996) desconoce si Garavaglia (1983) consigna los precios de venta de la yerba en pesos plata o «guecos», llevándolo a evaluar la ganancia teniendo en cuenta ambas posibilidades. Por su parte, Newland (2000) ha señalado la importancia de un estudio pormenorizado de los precios a la hora de evaluar el derrotero del comercio, sobre todo ateniendo a sus enormes divergencias a lo largo del imperio español. Ante la dificultad de encontrar fuentes completas y privadas que especifiquen precios de operaciones mercantiles, García Baquero (1976), Fisher (1985) y Jumar (2002; 2011) apelaron a los registros de navíos, aunque señalando la divergencia entre los aforos de las mercancías y sus precios de venta. Problema que comenzó a resolverse a partir de estudios de caso de Rodríguez Vicente (1975), García Baquero (1992) y Bernal (1992: 349-353). 
caso reciba el tratamiento pertinente, de acuerdo a los avances producidos por los especialistas.

De allí que tomemos al comerciante mayorista español, radicado en el Río de la Plata, Diego de Agüero, de quien obtuvimos una nutrida documentación comercial privada (correspondencia mercantil, cuadernos de cuentas y todo tipo de documentación comercial), la que fue analizada en perspectiva con fuentes públicas y seriales (registros de navíos y protocolos notariales). Gracias a ellas, realizamos una detallada aproximación a la medición de la ganancia mercantil a lo largo de la totalidad del período histórico en que se desenvolvió como comerciante mayorista (1770-1820), tanto en operaciones concretas como en el largo plazo, aunque dicho requerimiento implicó relegar otros aspectos (crédito en efectivo, administración de propiedades urbanas, acceso a cargos político-corporativos rentados, condiciones sociales que dinamizaron la acumulación), los que merecen un tratamiento particular que aquí no realizamos. Asimismo, aunque nos referimos a operaciones de contrabando (particularmente, a aquellas que han dejado rastros contables), nos concentramos en las operaciones legales de Agüero, dejando para otro momento un análisis del tráfico ilegal.

El primer problema que afrontamos a la hora de analizar el comercio de un individuo fue el de abordar voluminosas fuentes, a lo largo de medio siglo de historia, con el único fin de rastrear sus huellas. A ello se sumó que dicha documentación, para ser evaluada correctamente, implicó la visita a diversos archivos nacionales e internacionales, en tanto debimos confirmar el movimiento mercantil en mercados americanos y españoles. Así analizamos los registros de navíos del Archivo General de la Nación, de Argentina (AGNA), del Archivo General de la Nación de Montevideo (AGN-M), del Archivo General de Río de Janeiro (AGRdJ) y del Archivo de Indias de Sevilla (AGI) y los protocolos notariales resguardados en Buenos Aires y en La Plata (actual Sucre, Bolivia), a la par con la correspondencia y documentación privada de la Compañía Agüero, de la que se conservaron más de 4.000 cartas y 300 documentos contables, repartidos en sus archivos personales del Museo Histórico Nacional de la Argentina (MHN-A), el Museo Histórico Nacional de Uruguay (MHN-U), el AGN-A y el AGN-M. La recopilación, sistematización y análisis de la documentación implicó una tarea ardua, pero nos permitió contrastar una serie de fuentes que nunca habían sido utilizadas al mismo tiempo para un estudio de caso. 
Diego de Agüero, vecino y del comercio de Buenos Aires

Diego de Agüero nació en España, en la provincia de Santander, en $1738^{20}$. Llegó a Buenos Aires a mediados del siglo XVIII y desde los inicios de su actividad mercantil desempeñó funciones de mercader mayorista, integrando el núcleo de comerciantes más poderosos, conformado por Martín de Álzaga, José Martínez de Hoz y Jaime Alsina y Verjés, entre otros ${ }^{21}$. Dicho proceso de incorporación a la sociedad porteña fue profundizado en 1769 , mediante su matrimonio con Doña Petrona Alcántara Espinosa, hija de uno de los hacendados más poderosos del Río de la Plata 22 .

Con el correr del tiempo, Agüero adquirió un papel central en la sociedad colonial porteña. Participó en el Cabildo (en 1789 y 1792), formó parte de las Juntas de Comercio (desde 1780) y del Consulado de Buenos Aires, el que integró desde su fundación, como consiliario, tesorero y contador (1794-1802). A lo largo de este período, forjó relaciones corporativas y políticas que tuvieron por objetivo defender las condiciones que le permitían realizar su comercio. Entre ellas se destacó su vínculo con su sobrino y socio principal, Miguel Fernández de Agüero, quien participó activamente en la resistencia a las invasiones inglesas (1806-1807) y fue el último apoderado del Consulado de Cádiz en Buenos Aires (1804-1810). Como parte de esa tarea defendió los intereses gaditanos frente a la apertura de Buenos Aires al comercio inglés en 1809, auspiciada por los hacendados rioplatenses. El ocaso de su hegemonía llegó con la Revolución de Mayo y el fracaso del levantamiento contrarrevolucionario de 1812, el que profundizó el avance del gobierno sobre los españoles realistas, que alcanzó a llevar adelante dos juicios expropiatorios contra los Agüero (1814 y 1816).

A lo largo de su carrera, Agüero se dedicó a la importación de manufacturas europeas (textiles, en su inmensa mayoría), a cambio de metales preciosos (oro y plata amonedados) y producciones americanas (los llamados «frutos del país», fundamentalmente cuero y cobre). La estructura que sostuvo dicho giro se extendió desde la España y Portugal (Cádiz y Lisboa), hasta los principales mercados sudamericanos (principalmente Buenos Aires, Santiago de Chile, Potosí, Río de Janeiro, Córdoba, Mendoza, Salta, Jujuy, Lima, Chuquisaca, La Paz y Cochabamba). A partir de ella tuvo, en cincuenta años de carrera,

${ }^{20}$ Carta de Juan de Agüero a Diego de Agüero, 1 de septiembre de 1772, Museo Histórico Nacional de Montevideo (MHN-M), Archivo Diego de Agüero (AA). Herrera Vega y Jáuregui Rueda (2003: 835).

${ }^{21}$ Una descripción detallada de la vida de Agüero y de su derrotero político y corporativo en Schlez, 2011.

${ }_{22}$ Protocolos Notariales, Registro 3, Archivo General de la Nación Argentina (AGN-A). 


\section{Gráfico 1. Balanza Comercial de Diego de Agüero y Asociados. Río de la Plata - Península Ibérica (1770-1815)}

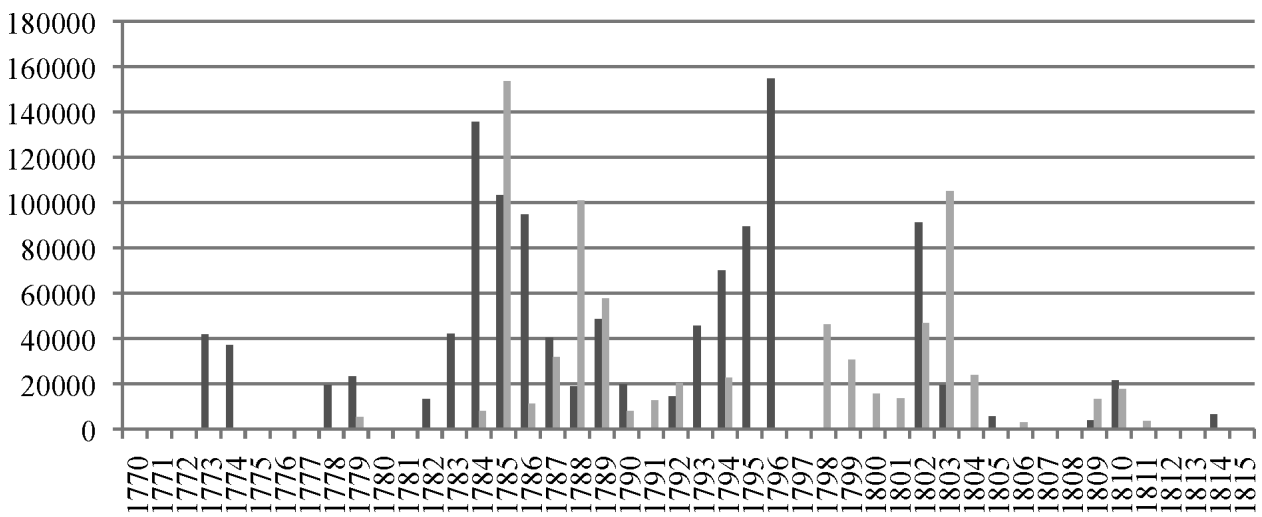

- Exportaciones de Caudales Importaciones de Mercancías

En pesos fuertes de América. A partir de los 4 reales, se pasa al peso siguiente.

Fuentes: AGN-A, Registros de Navíos (salas IX y XIII), Capitanía del puerto (sala III); Registros de Caudales (sala IX); Guías de Aduana (sala X). MHN-U, Fondo Ex Archivo y Museo Histórico Nacional, Aduana de Montevideo, Registros de Navíos; Fondo Archivo General Administrativo. AGI, Contratación; Indiferente General. AGRdJ, Fondo Cámara Municipal, Serie Embarcaciones, Termos de entrada no Porto do Río de Janeiro. Correspondencia, Cuentas Corrientes y Relaciones de Embarque. MHN-U, AA y AFA. AGN-U, Particulares. MHN-A, Sección libros copiadores del siglo XVIII y AGN-A: Sala IX, legajo 761, AA.

un notable desarrollo mercantil, que le permitió remitir a la metrópoli más de un millón de pesos fuertes, tal como prueba el siguiente gráfico.

Aquí podemos observar el balance comercial de las exportaciones e importaciones realizadas por Agüero y Compañía al interior del circuito legal español (excluida la exportación de frutos): 753.000 pesos en mercancías importadas y 1.163.633 de pesos en oro y plata exportados ${ }^{23}$. Es decir que existe una diferencia de 410.633 pesos a favor de la península ibérica, lo que nos permite intuir que el comercio de Agüero impulsó un flujo de riquezas que fue desde las colonias a la metrópoli, impresión que debe justipreciarse a partir de un análisis minucioso del lucro comercial.

${ }^{23}$ Debe tenerse en cuenta que a pesar de usarse los conceptos de exportación e importación desde el Río de la Plata, nos referimos a un movimiento mercantil que se desarrolla al interior del imperio español. Un mayor desarrollo sobre el volumen, contenido y sentido de la circulación impulsada por Agüero en Schlez, $2016 \mathrm{~b}$. 
Para ello analizamos los tipos de ganancia mercantil obtenidos por Agüero (comisionista y por cuenta propia), y los aspectos históricos, geográficos, sociales y políticos que la enmarcaron en tiempos de paz, de guerra y de Revolución. Comencemos, entonces, a dilucidar este problema yendo de los casos micro a los macro, es decir, del análisis de compra-ventas específicas, al cálculo del beneficio global.

\section{La ganancia mercantil comisionista}

Agüero comenzó a desarrollar su giro mercantil hacia 1770, como agente comercial de casas gaditanas, es decir, como comisionista. Esto implicó que su tarea fuese la de vender mercancías que no les pertenecían y obtener, a cambio, un porcentaje (comisión) de ganancia por dicha actividad. Es decir que, en los orígenes de su carrera, se dedicó a recibir, reenviar y vender mercancías de terceros (la mayoría de las veces de mercaderes gaditanos, aunque también de Santiago de Chile y Buenos Aires) y, a su vez, garantizar el retorno de las remesas de oro y plata o frutos del país (como el cuero y el cobre), en concepto de pago de dichos efectos vendidos. Agüero pudo desarrollar esta función gracias a que era un comerciante legalmente habilitado para traficar en Indias, en una ubicación social y geográfica privilegiada (un encumbrado integrante de la clase dominante porteña, con múltiples vínculos y relaciones a lo largo del imperio, residente en la capital del virreinato rioplatense) ${ }^{24}$.

En este tipo de comercio, los gastos eran afrontados por el propietario de las mercancías, quien se hacía cargo de la «cuenta» y el «riesgo» de una determinada operación ${ }^{25}$. El problema de la ganancia del comisionista, entonces, se vincula exclusivamente con la comisión acordada, que no siempre coincidía con lo estipulado por la ley. Ella se calculaba sobre el precio de venta al que eran vendidas las mercancías, por lo que el interés del propietario y el del comisionista coincidía en el objetivo de vender al máximo precio posible.

A fines del siglo XVIII, existía al interior del imperio español un parámetro consuetudinariamente establecido, que fijaba ciertos marcos, y que se expresaba en el ofrecimiento de Pedro Nolazco Valdes a Agüero, asegurándole que «por su trabajo y comisión podrá usted llevar lo que fuese corriente» ${ }^{26}$. Para ser más específicos, al momento de representar a compañías y casas de

\footnotetext{
${ }^{24}$ Schlez, 2013.

${ }^{25}$ Carta de Tomás de Carranza a Diego de Agüero, 26 de octubre de 1783, MHN-U, AA.

${ }^{26}$ Carta de Pedro Nolazco Valdés a Diego de Agüero, 2 de febrero de 1785, MHN-U, AA.
} 
comercio gaditanas, Agüero solía apropiarse de un porcentaje del $8 \%{ }^{27}$. No obstante, no se trataba de un monto fijo, y podía variar de acuerdo al tipo de operación y a la situación general del comercio. En momentos de crisis, por ejemplo, los gaditanos intentaban reducir los márgenes obtenidos por sus pares radicados en América, solicitándoles reduzcan el monto de su comisión. Así se lo planteó, en 1788, Pablo Páez Xaramillo, solicitándole «se sirva rebajar uno por ciento de los $8 \%$ que me carga de su comisión, bien entendido que mi propuesta no es violenta en la presente época, porque hace mucho tiempo corren estos asuntos en un pie de $6 \%$ en Lima, y aún en esa [Buenos Aires, n. del a.] ha habido sujeto conocido nuestro que ha llevado dicho interés» ${ }^{28}$.

Por otro lado, cuando los comerciantes radicados en América se consignaban mercancías entre sí, el porcentaje de la comisión solía reducirse al 4\%. De hecho, podemos considerar que se trataba de un monto reconocido en toda Sudamérica, en tanto las cuentas corrientes de Agüero con comerciantes de Córdoba, Mendoza, Chile y Potosí consignan el mismo porcentaje ${ }^{29}$. No obstante, al igual que lo ocurrido con la comisión cobrada a casas gaditanas, la establecida entre americanos no era única, y podía variar entre el $6 \%$ y el $3 \%$, aunque ellas apareciesen con menor regularidad que la más difundida del $4 \%{ }^{30}$.

Como podemos ver, la comisión que Agüero obtuvo de la venta y/o traspaso de mercancías fluctuó entre el 3\% y 4\% (monto que se cobraba entre comerciantes en América) y el 6\% y 8\% (que los radicados en América cobraban a sus pares gaditanos), pudiendo alcanzar, excepcionalmente, el 10\% establecido por la ley ${ }^{31}$. A pesar de estas fluctuaciones, el grueso de las ganancias comisionistas de Agüero rondaba el $7 \%$, por lo que podemos aproximarnos a su monto global sumando dicho porcentaje al volumen monetario total de mercancías traficadas por cuenta de terceros. A tal fin hemos confeccionado el cuadro 1, que realiza dicho cálculo a partir de los datos ofrecidos por los

${ }^{27}$ Carta de Pedro Páez Xaramillo a Diego de Agüero, 15/12/1784, MHN-U, AA.

${ }_{28}$ Carta de Pablo Páez Xaramillo a Diego de Agüero, 5 de agosto de 1788, MHN-U, AA.

${ }^{29}$ Cuenta de ventas, gastos y líquido de 4 petacas de grana propiedad de José Antonio Therán, del comercio de Córdoba, Miguel Fernández de Agüero, Potosí, 3/6/1794; Cuenta Corriente de Salvador de Trucios con Diego de Agüero, Santiago de Chile, 2/6/1781, AGN-A, Sala VII, Archivo Diego de Agüero (AA), leg. 761.

${ }^{30}$ El cobro del 3\% aparece en la Cuenta corriente de Diego de Agüero y Tomás de Carranza, 30/10/1787, Buenos Aires, MHN-U, AA, y es probable que se aplicase cuando Agüero hubiese oficiado de nexo necesario para el traslado de mercancías en América, aunque sin implicar transacción comercial alguna. Por su parte, podríamos considerar al $6 \%$ como un monto excepcional, en tanto aparece tan sólo en una oportunidad, cobrada por Juan Esteban de Ezcurra a Miguel Fernández de Agüero, desde Potosí, en febrero de 1796, Cuenta de ventas, MHN-U, Archivo Miguel Fernández de Agüero (AFA), tomo X.

31 Gelman, 1996. 
Cuadro 1. Ganancia comisionista obtenida por Diego de Agüero Y Asociados (1766-1811)

\begin{tabular}{|c|c|c|c|c|c|c|}
\hline Período & $\begin{array}{c}\text { Sentido } \\
\text { del comercio }\end{array}$ & $\begin{array}{c}\text { Neto } \\
\text { cargado }\end{array}$ & $\begin{array}{c}\text { Valor } \\
\text { de Aforo }\end{array}$ & $\begin{array}{c}\text { Costo } \\
\text { estimado } \\
(+20 \%)\end{array}$ & $\begin{array}{c}\text { Ganancia } \\
\text { media } \\
(+35 \%)\end{array}$ & $\begin{array}{c}\text { Ganancia } \\
\text { Agüero } \\
(7 \%)\end{array}$ \\
\hline \multirow{2}{*}{1770} & Importaciones & & 325.162 & 390.194 & 526.762 & 36.873 \\
\cline { 2 - 7 } 1811 & $\begin{array}{c}\text { Exportaciones } \\
\text { de caudales }\end{array}$ & 727.634 & & - & - & 50.934 \\
\hline \multicolumn{7}{|c|}{ Total } \\
\hline
\end{tabular}

(+/-3\%). En pesos fuertes de América.

Fuente: ídem gráfico 1.

registros de navíos de entrada y salida de los puertos de Buenos Aires, Montevideo, Cádiz y Lisboa, los que concentraban la totalidad del giro de Agüero.

Naturalmente, debemos tener en cuenta que estos 87.807 pesos fuertes son el resultado de un acercamiento mediado por una serie de variables que escapan a una ponderación exacta. Así como existieron diferentes porcentajes de comisión, obligándonos a tomar el más representativo para realizar el cálculo, también es cierto que no podemos saber cuándo Agüero efectivamente cobró una comisión y cuándo no lo hizo. Existen documentos de ventas que no especifican su existencia, pero resulta imposible saber si ella no se cobró (por haberse realizado al interior de una sociedad específica, por ejemplo), si se encuentre incluida en otros gastos (como ocurría en el caso del otorgamiento del crédito, donde la suma que figura en los protocolos notariales engloba tanto el principal como el interés cobrado), o si aparece en otro tipo de documento no conservado.

Por otro lado, en el cuadro se reconstruye la acumulación que le habría aportado el comercio comisionista a Agüero utilizando los registros de navíos. Ellos señalan el valor de aforo que tenían las mercancías en Cádiz, y no su precio de compra en Cádiz ni, mucho menos, el de venta en América. Dato que mejoramos comparando los aforos (establecidos en el Reglamento de Libre Comercio de 1778) con los precios de venta en Cádiz consignados en las cuentas privadas de Agüero. Ello nos mostró, en los casos analizados, un desfasaje entre aforo y precio que rondaba un $20 \%$, por lo que intentamos aproximar ambos valores aumentando el volumen total (calculado a partir de los aforos de los registros de navíos) en ese porcentaje (el 20\% que las cuentas privadas muestran existía de diferencia con el precio). 
Finalmente, nos encontramos con el problema de que la comisión se calculaba como porcentaje, o bien del precio de venta de los géneros en América, o bien del costo que tuvo un determinado movimiento comercial (como la carga de caudales en el puerto, o la puesta en marcha de una tropa con dirección al interior americano). No obstante, nos es imposible conocer los precios y costos de la totalidad de operaciones realizadas a lo largo de más de cincuenta años, dado que no se han conservado las cuentas de cada una de ellas, por lo que no podemos conocer los márgenes de ganancia exactos de cada una. Nuevamente, nos vemos obligados a aproximarnos al volumen global del beneficio de Agüero a través de un cálculo general con los datos que poseemos. Es así como, una vez más, intentamos llevar el valor de aforo a un nivel más cercano al de los mercados, es decir, sumándole la ganancia mercantil estimada para la época y la región, de acuerdo a las cuentas de venta analizadas. Ellas prueban el carácter aleatorio de los precios y dan cuenta de ganancias completamente dispares, de entre el $25 \%$ y el $135 \%$, a los que deben sumarse los casos en que las mercancías fueron a completa pérdida. No obstante, observamos que, descartando las pérdidas y los casos excepcionales de márgenes relativamente altos (mayores al 60\%), las cuentas de ventas conservadas nos permiten asegurar que Agüero obtuvo, como promedio mínimo, un margen de ganancia del $35 \%$. Por esta razón, aumentar en ese porcentaje el volumen monetario general calculado nos condujo a un monto aproximado de su ganancia.

No obstante estas consideraciones, es evidente que la suma resultante debe ser considerada como una cantidad mínima. En primer lugar, porque sólo incluimos en el cuadro las facturas dirigidas a Agüero, desechando aquellas en las que figuraba como segundo o tercer destinatario, aun sabiendo que, en numerosas oportunidades, fue él quien terminó haciéndose cargo de la tarea. En segundo, debido a que no pudimos sumar a nuestro cálculo la enorme cantidad de compra-ventas de productos americanos que realizó Agüero, por cuenta de terceros, en los mercados americanos (y que nunca pasaron por la aduana marítima porteña). Aunque tenemos noticias de ellas en su documentación privada, un análisis sistemático, similar al realizado con los registros de navíos, habría implicado la revisión y sistematización de la totalidad de guías y notas de aduana a lo largo de cincuenta años de historia, tarea difícil de alcanzar por un individuo en un período razonable de trabajo ${ }^{32}$. Y tampoco nos ayudaron los protocolos notariales, debido a que sus actas no distinguen

${ }^{32}$ Se trata de las notas mediante las cuales los comerciantes solicitaban autorización al Estado para poner bienes en circulación. Fernando Jumar y Silvia Mallo conformaron un equipo de 12 investigadores para sistematizar unos 15.000 documentos, correspondientes a tan sólo cinco años de comercio (1779-783). Jumar (2010) reconoce que se trata de una «fuente 
la propiedad de las mercancías transadas, por lo que nos fue imposible dilucidar qué magnitud, de un total de 509.896 pesos de 8 reales fiados por Agüero, correspondió al comercio comisionista ${ }^{33}$. En tercero, porque hemos excluido, por el momento, la exportación de frutos americanos, debido a que los registros no dan cuenta del valor de aforo.

\section{La ganancia mercantil por cuenta propia}

Una vez consolidada su posición, a fines de la década de 1770, Agüero comenzó un giro mercantil por cuenta propia, que no dependía de la consignación de mercancías de terceros. Lamentablemente, el cálculo de la ganancia cuentapropista es más complicado que la del comisionista, en tanto hay que contemplar la estructura de costos que implicaba el comercio. Es decir que para calcular la ganancia debemos tener en cuenta el costo de las mercancías, su precio de venta y los gastos implicados en dicha tarea, incluyendo el costo del transporte (marítimo y terrestre), los gastos de descarga y almacenaje, los impuestos estatales, el seguro de las mercancías, la prima de los créditos, el costo y premio de las monedas de oro y plata que se remitían a la metrópoli y, finalmente, las condiciones y forma de pago de cada una de las ventas (efectivo, plazo del fiado o «cambalache» por otros géneros). A todo ello debemos sumarle la necesidad de evaluar la depreciación de ciertos elementos de cambio (como los vales reales) y las condiciones políticas que encuadraban la actividad mercantil (fundamentalmente, guerras y revoluciones) ${ }^{34}$.

rica en informaciones, aunque de explotación muy compleja para los modos tradicionales de trabajar o para un esfuerzo individual».

${ }_{33}$ Protocolos Notariales, Registros 1 al 7, 73, 74 y 76, AGN-A.

34 Por «premio» de las monedas entendemos el valor extraordinario que ofrecían el oro y la plata por encima de su valor oficial o legal. La enorme variedad de monedas existentes en el Imperio español, determinaba que, las más poderosas, obtuviesen un premio, es decir, que se paguen en determinados mercados (como Buenos Aires o Cádiz) a un valor mayor de lo que determinaba la ley. Dicho premio que pagaban las monedas de oro y plata en Buenos Aires y Cádiz variaba de acuerdo a la abundancia o escasez coyuntural de dichas mercancías y a la demanda que los comerciantes (mayoritariamente) tuviesen de ellas. Algunas estimaciones calculan, para la Buenos Aires de principios de la década de 1770, un premio del 3\% para la plata, y de un $8 \%$ para el oro. Sobre el tema, ver Álvarez (1929). Por su parte, nos referimos por «cambalache» al trueque de mercancías de difícil venta, o que no han podido ser realizadas al precio esperado, y que resultan finalmente intercambiadas por el mercader por otro producto más necesario. Finalmente, los «vales reales» fueron bonos que el Estado español puso en circulación en 1780, para financiar su apoyo a los nacientes Estados Unidos de América, en su guerra contra Gran Bretaña. Algunos historiadores los consideran el primer 
Es evidente la imposibilidad de realizar dicho cálculo para cada compraventa realizada en cincuenta años de comercio, fundamentalmente porque no se han conservado libros contables completos. Iremos, entonces, de lo micro a lo macro, evaluando las características de ciertas operaciones concretas, para pasar luego a una estimación global.

La primera sociedad por cuenta propia fue creada por Agüero en 1779, con Tomás de Carranza, comerciante radicado en Santiago de Chile, que se disponía a regresar a España. Dividiendo todos los gastos por mitades, Carranza realizaría las compras en Cádiz y Agüero vendería las mercancías en Sudamérica, remitiendo el resultado de las ventas a su socio, preferentemente en oro y plata (aunque también en cobre), para reiniciar el ciclo mercantil. Comenzaremos a observar la ganancia que ambos obtuvieron, evaluando los resultados de su primera operación mercantil, la que resumimos en los siguientes cuadros.

El cuadro 2 nos ofrece un panorama claro de los objetivos de la sociedad: comprar géneros en Cádiz (en esta oportunidad, todos extranjeros), trasladarlos a América y, allí, venderlos por la mayor ganancia posible. El primer elemento a destacar de la cuenta de venta elaborada por Agüero es el porcentaje de ganancia obtenido, que rondó el $60 \%$. No obstante, es evidente que los socios no se apropiaron de esa diferencia, en tanto debe deducirse de allí una serie de costos y gastos, los que enumeramos en el cuadro 3.

Aquí vemos cómo los costos que debían afrontar los comerciantes coloniales podían hacerles esfumar sus ganancias, y se evidencia que el seguro, la prima del crédito solicitado para la compra, los gastos de transporte y almacenaje y los derechos cobrados por el Estado español dejaron a la sociedad mercantil con un magro resultado.

Uno de los elementos que influyó en esta situación acuciante fue la guerra anglo-española (1779-1783). Los géneros llegaron al Río de la Plata en agosto de 1779 y Agüero concluyó su venta tres años después, en junio de 1782, fecha en que confeccionó la cuenta de ventas, líquido y gastos. Por un lado, la guerra le permitió obtener un buen margen de ganancia en la venta, en tanto la detención del giro atlántico favoreció a los comerciantes que ya poseían mercancías en América y podían especular con la escasez reinante. No obstante, dicho beneficio se resintió, en primer lugar, por la imposibilidad de remitir los caudales a España (por el peligro de que sean capturados por los

papel moneda de la historia española, aunque, en su calidad de bonos, los vales fueron premiados con réditos de interés de a un $4 \%$ sobre su valor nominal. Naturalmente, su función y resultados económicos concretos varió en las diferentes regiones del imperio. Al respecto pueden consultarse Vázquez Cienfuegos y Santamaría García, 2012 y Schmidt, 2004. 


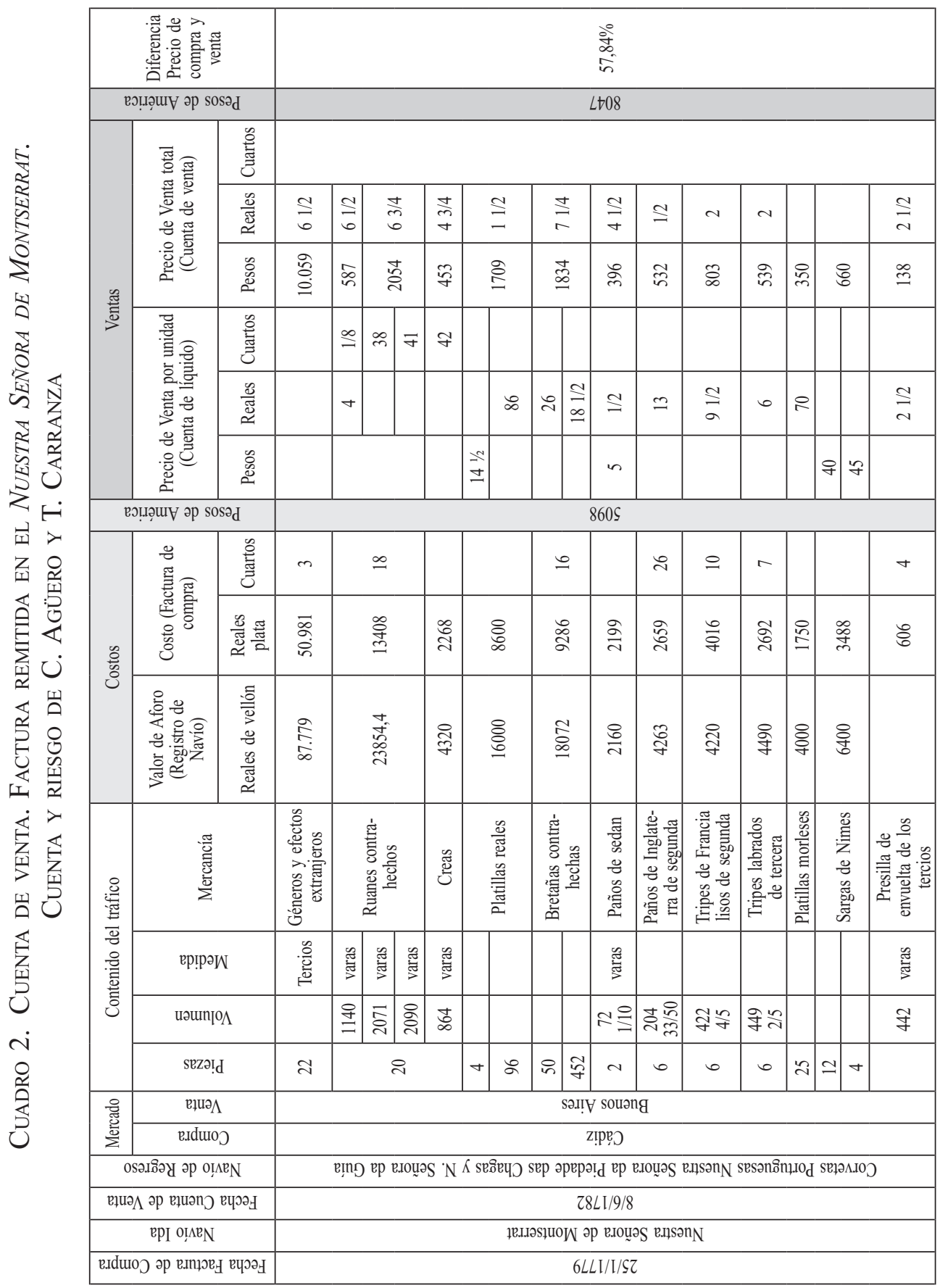




\begin{tabular}{|c|c|c|c|c|}
\hline \multirow{11}{*}{ 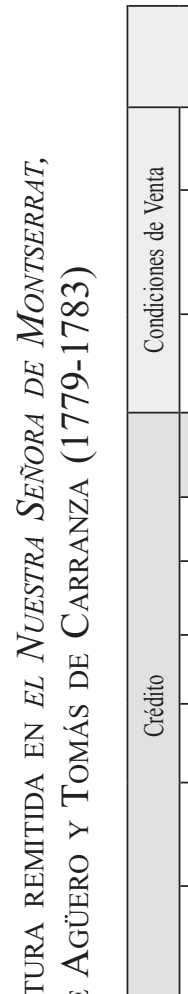 } & \multicolumn{2}{|c|}{ 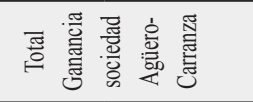 } & \multicolumn{2}{|c|}{ 导 } \\
\hline & \multicolumn{2}{|c|}{ 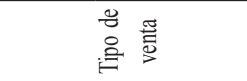 } & \multicolumn{2}{|c|}{ 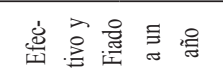 } \\
\hline & \multicolumn{2}{|c|}{ 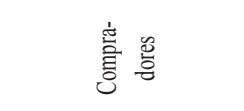 } & \multicolumn{2}{|c|}{ 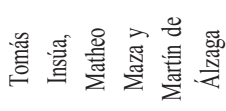 } \\
\hline & \multicolumn{2}{|c|}{ 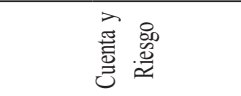 } & \multicolumn{2}{|c|}{ 总 } \\
\hline & \multicolumn{2}{|c|}{ 홍 : 旁 } & \multicolumn{2}{|c|}{ \& } \\
\hline & \multicolumn{2}{|c|}{ 梂 } & \multicolumn{2}{|c|}{ 胥 } \\
\hline & \multicolumn{2}{|c|}{ 魚 } & \multicolumn{2}{|c|}{ bे } \\
\hline & \multicolumn{2}{|c|}{ 总 } & \multicolumn{2}{|c|}{$\begin{array}{l}\stackrel{8}{\infty} \\
\stackrel{+}{+}\end{array}$} \\
\hline & \multicolumn{2}{|c|}{ 葋 } & \multicolumn{2}{|c|}{ 燕 } \\
\hline & \multicolumn{2}{|c|}{$\begin{array}{l}\text { 题 } \\
\text { 总 } \\
0\end{array}$} & \multicolumn{2}{|c|}{ 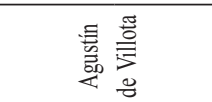 } \\
\hline & \multicolumn{2}{|c|}{ 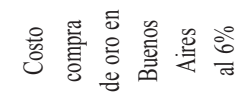 } & \multicolumn{2}{|c|}{$\cong$} \\
\hline 屋 & \multicolumn{2}{|c|}{ इే } & \multicolumn{2}{|c|}{$\stackrel{\infty}{\infty}$} \\
\hline คิ & \multirow{2}{*}{ 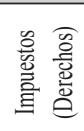 } & $\frac{\pi}{3}$ & \multicolumn{2}{|c|}{ 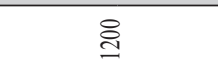 } \\
\hline$\vec{\theta}$ & & 胥 & \multicolumn{2}{|c|}{$\dot{\infty}$} \\
\hline 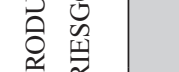 & \multirow{2}{*}{ 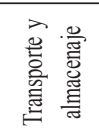 } & $\frac{\pi}{9}$ & \multicolumn{2}{|c|}{$\approx$} \\
\hline & & 急 & \multicolumn{2}{|c|}{ 导 } \\
\hline 点占 & \multirow{6}{*}{ 总 } & \multirow{3}{*}{ 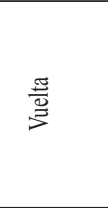 } & 递 & $\frac{2}{n}$ \\
\hline & & & 核 & $\frac{D}{\infty}$ \\
\hline & & & 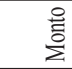 & $\frac{\partial}{n}$ \\
\hline 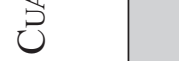 & & & $\frac{8}{3}$ & $\approx$ \\
\hline & & 巴ँ & 萢 & ì \\
\hline & & & 退 & ৪্ল \\
\hline
\end{tabular}

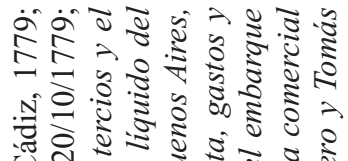

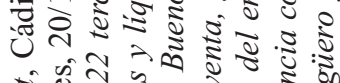

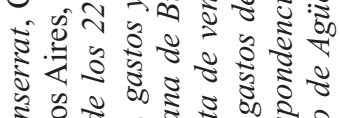

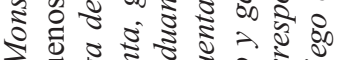
0
0

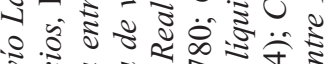

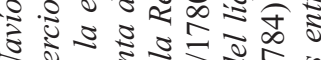

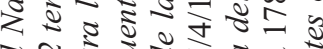

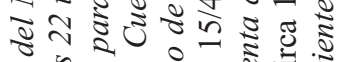

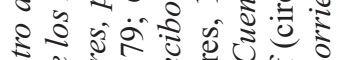

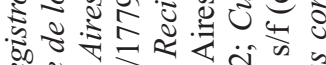

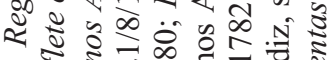

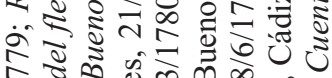
三

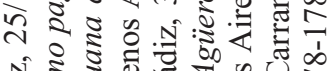

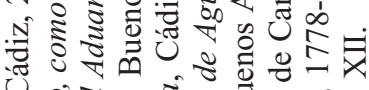

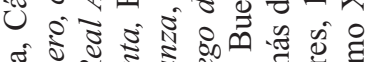

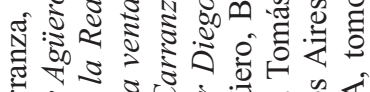

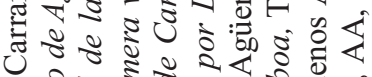

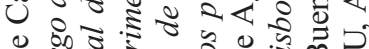

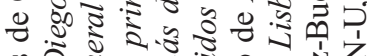
สิ

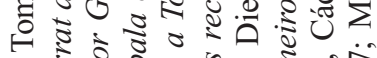
की

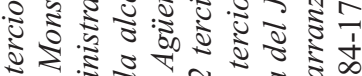
กิป

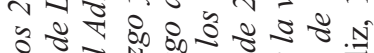

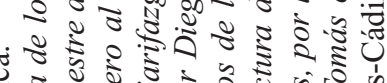

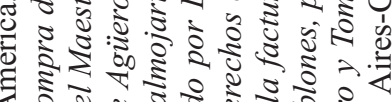

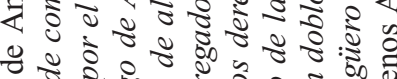

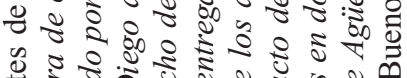

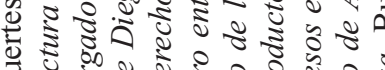

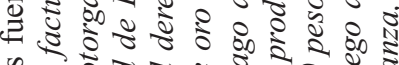

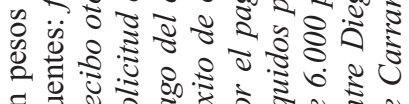

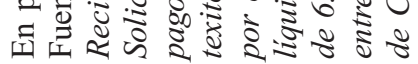


ingleses), acrecentando notablemente el interés a pagar por el crédito adeudado en Cádiz, que no pudo ser cancelado en tiempo y forma (el cuadro muestra que se pagaron 778 pesos, en lugar de los 360 acordados). Asimismo, luego de que la sociedad decidiera remitir los caudales «por la vía del Janeiro a Lisboa» ${ }^{35}$, a través de la Compañía Ustáriz, ellos llegaron retrasados debido a que buques enemigos impidieron su salida del Río de la Plata y provocaron su arribo tardío al Brasil. Ello generó una serie de gastos extraordinarios a los que accedimos gracias al recibo que Carranza remitió a Agüero: 11\% sobre los 6.000 pesos en doblones recibidos desde Buenos Aires, es decir, 660 pesos fuertes.

Es decir que la guerra fue uno de los factores que dieron por tierra con la ganancia de la negociación, permitiéndole a Agüero y Carranza rescatar para sí apenas un 4,8\%, sobre el $60 \%$ obtenido en la venta de los géneros. Para evaluar los elementos centrales de la estructura de costos, el cuadro 4 resume el reparto de la ganancia bruta (60\%) obtenida con la venta de los géneros en América.

La ganancia comercial se repartió entre dos grandes sujetos sociales: el capital mercantil (en sus diversas fracciones) y la monarquía (quien recibió su parte a través del cobro de derechos a la circulación). En este sentido, mientras que los Estados (español y portugués) se apropiaron del 53,7\%, el capital mercantil obtuvo el restante 46,2\%. Al interior de éste, la porción mayor de beneficio fue apropiada por fracciones especializadas en otorgar crédito, seguro y diferentes tipos de servicios (cambio de dinero, transporte y almacenaje): mientras que todos ellos se quedaron con un $41,5 \%$, el capital mercantil «puro» (Agüero y Carranza), tan sólo obtuvo un 4,8\%.

A partir de estos datos, no sólo debemos considerar la guerra anglo-española como un factor central en el reparto de la ganancia, sino también las consecuencias que tuvo en la agudización de la competencia mercantil, profundizada por la puesta en práctica del Reglamento de $1778^{36}$. A ellas deben sumarse problemas resultantes del grado de acumulación de la compañía de Agüero, que le imposibilitó ampliar el espectro de tareas asumidas, obligán-

${ }^{35}$ Cuenta del líquido y gastos del embarque de 6.000 pesos en doblones, por la vía del Janeiro a Lisboa, Tomás de Carranza, Cádiz, s/f (circa 1784), en MHN-U, AA, tomo XII.

${ }^{36}$ La guerra entre España e Inglaterra que se desarrolló entre 1779 y 1783, dañó al comercio colonial español de dos maneras: en primer lugar, aminoró notablemente el flujo de comercio durante el período de guerra y, en segundo, provocó una agudización de la competencia a su finalización, en tanto los géneros acumulados en España durante el conflicto invadieron los mercados americanos a partir de 1783-1784, provocando una saturación que llevó a un descenso de los precios y a la quiebra de numerosas compañías mercantiles. Al respecto, véase Bernal, 1992: 419. 
Cuadro 4. Reparto de la ganancia mercantil obtenida por la venta de la

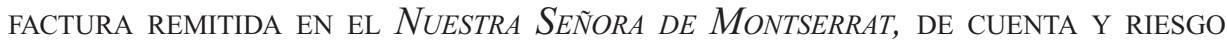
de Diego de Agüero y Tomás de Carranza

\begin{tabular}{|c|c|c|c|c|}
\hline \multicolumn{2}{|c|}{ Ganancia } & Categoría & Apropiado por & $\%$ \\
\hline \multirow{6}{*}{2949} & 96 & Seguro & \multirow{4}{*}{$\begin{array}{l}\text { Fracciones especializa- } \\
\text { das del capital mercan- } \\
\text { til y financiero }\end{array}$} & \multirow{4}{*}{41,5} \\
\hline & 778 & Crédito & & \\
\hline & 175 & $\begin{array}{c}\text { Transporte y almace- } \\
\text { naje }\end{array}$ & & \\
\hline & 170 & $\begin{array}{l}\text { Conversión monetaria } \\
\text { (compra de oro) }\end{array}$ & & \\
\hline & 1587 & Derechos y gravámenes & $\begin{array}{c}\text { Estado } \\
\text { (español y portugués) }\end{array}$ & 53,7 \\
\hline & 143 & Ganancia & Comerciantes & 4,8 \\
\hline
\end{tabular}

En pesos fuertes de América.

Fuentes: ídem cuadro 3.

dolo a tercerizar servicios (crédito para adquirir los géneros, transporte y almacenamiento para movilizarlos y conservarlos) que provocaron un notable descenso de su rentabilidad y la transferencia de altos porcentajes de ganancia a otros sectores del capital ${ }^{37}$.

Dado que ambos socios eran conscientes de estos problemas, no parece radicar en su estrategia empresarial el núcleo del asunto, si no en el escaso desarrollo de su empresa y su imposibilidad para llevar adelante las tareas que se proponían. El cuadro 5 resume el derrotero de la sociedad, a través del análisis de sus cuentas de ventas y cuentas corrientes, y muestra la persistencia de esta situación.

${ }^{37}$ Aunque Agüero resolvió el problema del crédito al aumentar su propio caudal de acumulación y evitar la necesidad de solicitar préstamos a terceros (e, incluso, comenzar a ofrecer él mismo créditos a comerciantes mayoristas), en su carrera no se dedicó al otorgamiento de seguros, aspecto que continuó siendo un problema hasta los días finales de su giro. Véase Schlez, 2010. 


\begin{tabular}{|c|c|c|c|}
\hline 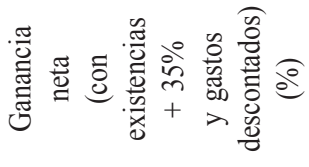 & & $\underbrace{\sigma_{0}}_{i}$ & $\begin{array}{l}\infty \\
\stackrel{q}{q}\end{array}$ \\
\hline 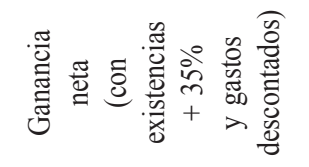 & 1 & $\infty_{1}$ & 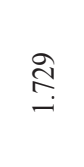 \\
\hline 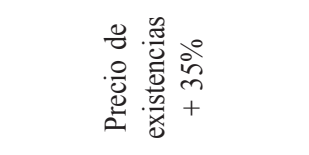 & ' & 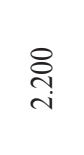 & $\begin{array}{l}8 \\
\infty \\
\infty \\
\text { n. }\end{array}$ \\
\hline$\partial^{\circ}$ & $\begin{array}{l}\infty \\
\forall\end{array}$ & $\stackrel{\vec{r}}{\vec{r}}$ & $\vec{\sigma}_{0}$ \\
\hline 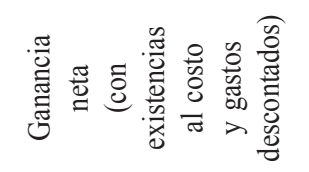 & $\stackrel{?}{\Xi}$ & : & $\stackrel{\circ}{n}$ \\
\hline 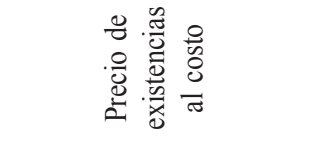 & 0 & $\underset{0}{ \pm}$ & $\begin{array}{l}\overrightarrow{\widetilde{d}} \\
\text { i } \\
i\end{array}$ \\
\hline 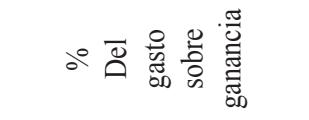 & బै & $\underset{\sim}{\mathbb{\infty}}$ & $\stackrel{\infty}{\infty}$ \\
\hline 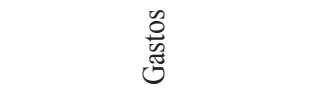 & $\begin{array}{l}\underset{\infty}{\infty} \\
\stackrel{\sim}{i}\end{array}$ & $\frac{a}{n}$ & 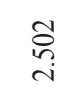 \\
\hline$+\widehat{e}$ & $\begin{array}{l}\infty \\
i n\end{array}$ & $\stackrel{m}{=}$ & $\vec{m}$ \\
\hline 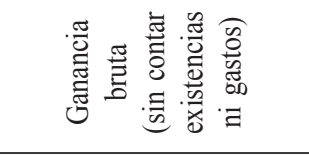 & dे & సે & $\bar{F}$ \\
\hline 吕 & 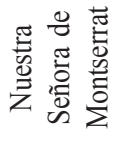 & 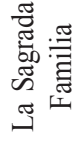 & 苞 \\
\hline 是 & $\stackrel{2}{\stackrel{2}{I}}$ & $\stackrel{+}{\stackrel{ \pm}{\Xi}}$ & $\stackrel{\infty}{=}$ \\
\hline
\end{tabular}


El cuadro 5 parte de la ganancia bruta, obtenida luego de las liquidaciones realizadas por Agüero. Por «bruta» queremos decir sin gastos y sin las existencias que pudiesen haber quedado sin vender, consignada tanto en pesos como en el porcentaje de aumento (respecto de los precios de los efectos en Cádiz). Luego señalamos los gastos que cada operación tuvo, también expresados en pesos y en el porcentaje de la ganancia que la sociedad tuvo que destinar para su pago. Sigue a ellos el precio de las existencias al costo, para evaluar la ganancia obtenida si ellas se hubiesen vendido sin ningún beneficio (luego del cierre de la cuenta de ventas). Finalmente, consignamos el precio de las existencias con un $35 \%$ de aumento, para medir la ganancia en el caso de haberse vendido los géneros existentes con el margen más representativo que estipulamos para Agüero.

Los datos muestran que la sociedad Agüero-Carranza, pese a sus esfuerzos, no produjo ganancias sustantivas. E insistimos en la influencia de un elemento coyuntural: la agudización de la competencia, a mediados de la década de 1780. Ella les costó, a ambos comerciantes, la totalidad de la ganancia de la factura de «La Sagrada Familia», la primera que llegó a América luego de la finalización de la guerra con Inglaterra, junto a las toneladas de ropas acumuladas en la península ibérica durante el conflicto, y que inundaron América luego de su finalización. Debido a ello, Agüero requirió de una importante cantidad de tiempo para vender sus mercancías y, de hecho, al realizar la cuenta de ventas en 1787, aún no se desprendía de todo. Asimismo, la coyuntura lo obligó a vender buena parte de ellas a un margen mucho menor de ganancia, que apenas alcanzó el 30,5\% (muy distante del $60 \%$ obtenido anteriormente).

Situación que llevó a ambos comerciantes al contrabando, que tenía por objetivo acrecentar sus márgenes de ganancia. Fue así como la operación del «San Fernando» incluyó la venta de géneros extranjeros no declarados al Estado español, lo que evidencia que Agüero y Carranza eran conscientes del enorme peso que implicaban los impuestos estatales a la circulación, e hicieron lo posible por evitarlos ${ }^{38}$. Dicho contrabando les permitió ahorrar una parte sustantiva de los gastos abonados en concepto de derechos, aunque tampoco alcanzó para hacer «despegar» a la compañía, la que enfrentaba obstáculos sociales más generales a su desarrollo.

En síntesis, consideramos que la experiencia de la primera sociedad por cuenta propia de Agüero, aunque no modificó de manera sustantiva su nivel de acumulación, le permitió sobrevivir al período de mayor competencia del comercio colonial y, al mismo tiempo, le otorgó a Agüero una serie de recursos (experiencia, contactos y riquezas, tanto en forma de metales como de géneros

${ }^{38}$ Factura de 27 tercios que viajan, de cuenta y riesgo de Tomás de Carranza y Diego de Agüero, en el navio 'San Fernando', Cádiz, 30/4/1785, MHN-U, AA, tomo I. 
acumulados) que le permitieron no sólo sostener su giro, sino también sentar las bases de un salto cualitativo.

\section{La Sociedad Agüero - Fernández De Agüero}

Luego de la sociedad con Tomás de Carranza (1779-1787), Agüero estableció una nueva compañía mercantil con su sobrino, Miguel Fernández de Agüero (a quien había educado desde su arribo a Buenos Aires, en 1778, con 13 años de edad), que perduró hasta la crisis terminal del comercio colonial. En este nuevo emprendimiento, Agüero sostuvo su posición en Buenos Aires, determinando que sea Miguel quien se traslade a Cádiz (1787 a 1792 y 1796 a 1804) y Potosí (1793 a 1795). Dado que no se ha conservado un número sustantivo de cuentas de venta, nos aproximaremos a la ganancia obtenida a partir del volumen global de su balanza comercial atlántica, en vinculación a las especificidades de las ventas en los mercados americanos.

\section{El volumen mercantil}

Un primer acercamiento a la ganancia cuentapropista de los Agüero resulta de una medición del dinero invertido en la adquisición de las mercancías. Para ello hemos construido un gráfico que resume tanto el volumen monetario de las importaciones de géneros, desde Cádiz y Lisboa, por cuenta de la sociedad, como la cantidad de metales preciosos que fueron remitidos a la península ibérica en forma de pago.

El gráfico 2 muestra que el volumen monetario destinado a la compra de efectos es sustantivamente mayor al de la década previa, importando los Agüero mercancías por, aproximadamente, 344.107 pesos fuertes.

Establecido su poder de compra, es pertinente preguntarnos por la ganancia que debería haberles producido dicha inversión. Lamentablemente, una serie de elementos dificultan una mirada más certera, fundamentalmente la completa aleatoriedad de los precios de venta en América, la variabilidad de los costos del tráfico (desde el seguro hasta el transporte, pasando por los derechos múltiples por la necesidad de atravesar el imperio portugués para llegar a Cádiz) ${ }^{39}$, la incertidumbre generada por la coyuntura bélica internacional, la

${ }^{39}$ Demostración de lo que contribuyen los géneros extranjeros (que abajo se expresan) a su entrada en los puertos de España sobre buques extranjeros o nacionales, MHN-U, AA, tomo XIV. 
GrÁFICO 2. EXPORTACIONES DE CAUDALES E IMPORTACIONES DE MERCANCÍAS Por cuenta y Riesgo de Diego de Agüero y Compañía (1784-1811)

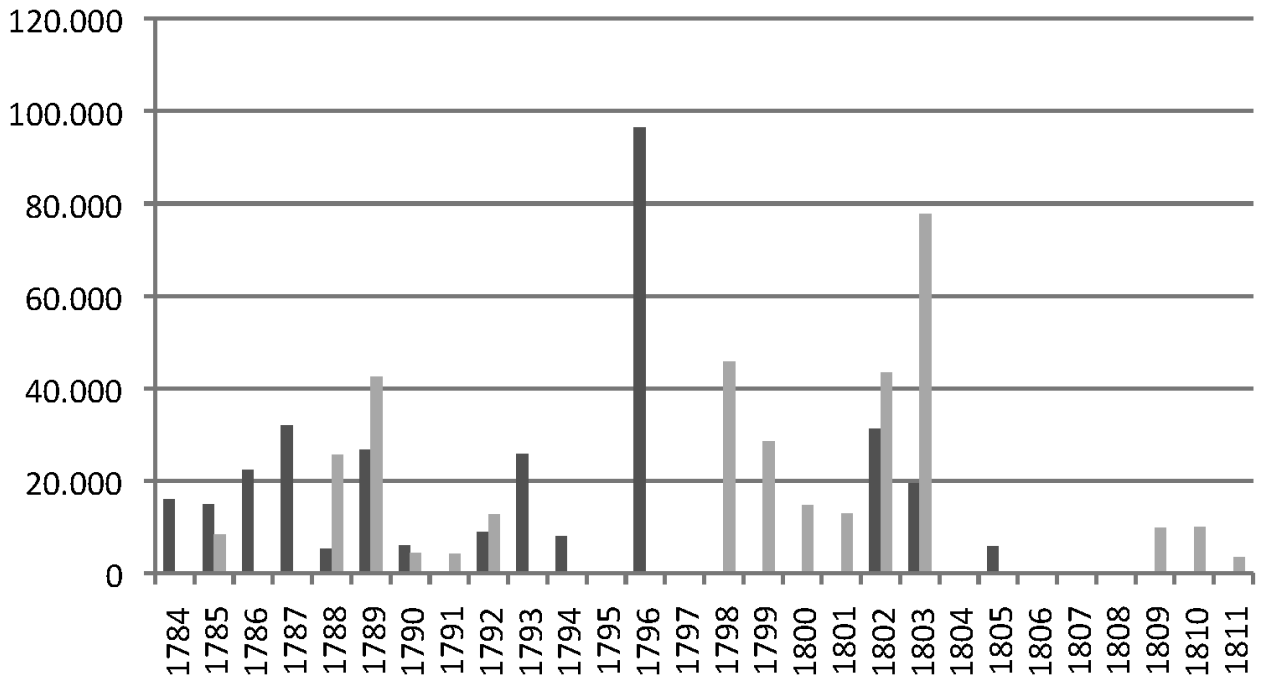

Remesas de caudales Importaciones de mercancías

En pesos fuertes de América.

Fuentes: ídem gráfico 1.

incapacidad de los seguros para hacer frente a las permanentes pérdidas de naves en altamar ${ }^{40}$ y la difusión de los vales reales españoles, que se depreciaban al calor de la crisis.

No obstante este conjunto de situaciones y variables diversas que dificultan el cálculo de la ganancia comercial, encontramos una primera confirmación del volumen mercantil cuentapropista manejado por los Agüero gracias a la medición del sentido contrario de su flujo mercantil, es decir, de la remisión de oro y plata por su propia cuenta a la península ibérica, para la adquisición de las mercancías importadas. En este sentido, existe una diferencia cualitativa fundamental con los negocios previos: en esta oportunidad, Agüero aporta el total del dinero necesario para los gastos, sin recurrir a ningún tipo de préstamo de terceros (con excepción de un pequeño monto solicitado por Fernández de Agüero en Cádiz). De allí que las remesas de oro y plata por cuenta propia de Diego de Agüero expresan los niveles de acumulación alcanzados,

${ }^{40}$ Cuenta corriente con premios y pérdidas de seguros de Diego de Agüero, Miguel Fernández de Agüero, Cádiz, 30/2/1797, MHN-U, AA, tomo XIV. 
en tanto se trata de dinero que ni ha sido solicitado a crédito, ni viaja como retribución de venta a una casa de comercio gaditana. Por el contrario, tiene como destinatario al otro integrante de la sociedad, quien debe reinvertirlo pura y exclusivamente en la compra de géneros y efectos, para devolver la riqueza al Río de la Plata bajo la forma de remesas de mercancías. Es decir que, atendiendo a esta lógica, debiera existir una cierta correspondencia entre los caudales remitidos y el costo de las mercancías despachadas desde Cádiz al Río de la Plata, lo que efectivamente muestra el gráfico 3.

Nuestros cálculos consolidan la imagen de un giro cuentapropista que supera holgadamente los 300.000 pesos fuertes. Esta mayor capacidad de acumulación, además de haberse beneficiado por la ausencia de solicitud de créditos, creció desde comienzos del siglo XIX, cuando los Agüero disminuyeron aún más su estructura de costos al adquirir un navío propio, con el cual no tener que delegar en terceros el gasto de flete. Es decir que la sociedad Agüero desplegó una estrategia comercial que eliminó algunas de las variables que habían disminuido la ganancia en su experiencia previa: el aumento de su escala de acumulación le permitió renunciar a la solicitud de créditos y adquirir medios de transporte marítimo propios.

Finalmente, debemos tener en cuenta que el volumen calculado de 300.000 pesos fuertes representa una cantidad mínima, en tanto ya hemos explicado

GrÁfico 3. Exportaciones de CAUDALES E IMPORTACIONES DE MERCANCÍAS POR cuenta y Riesgo de Diego de Agüero y Compañía (1784-1811)

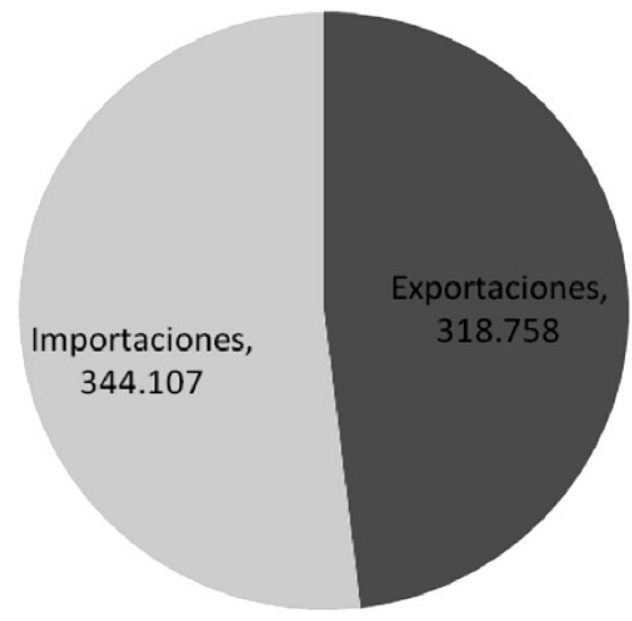

En pesos fuertes de América.

Fuentes: ídem gráfico 1. 
que las remesas de metales preciosos sólo tuvieron por objetivo la compra de mercancías en Cádiz. De ello se desprende que la sociedad Agüero no se vio obligada a remitir sus ganancias a España, por lo que su fortuna tuvo como eje de acumulación a la ciudad de Buenos Aires. Por lo que intentaremos acercarnos a los márgenes que dicha ganancia podría haber producido analizando la importación de géneros y la exportación de frutos.

\section{La ganancia en la importación de géneros}

Ya señalamos el entrelazamiento entre la importación, venta y reexportación de utilidades que implicaba el comercio colonial. En este sentido, las remesas de metales preciosos que Diego de Agüero realizaba a su socio en Cádiz provenían, en gran medida, de los pagos recibidos de sus socios de Mendoza, Córdoba, Santiago del Estero y, fundamentalmente, Chile y Potosí, que en tan sólo cinco años remitieron a Buenos Aires más de 44.000 pesos fuertes, los que reinvertidos en España permitían reiniciar el ciclo comercial.

Expresión de este espiral ascendente fue el segundo viaje de Miguel Agüero a Cádiz, entre 1796 y 1804, el que fue documentado minuciosamente en forma de informes regulares remitidos al Río de la Plata ${ }^{41}$. Ellos muestran que Diego de Agüero aportó el dinero necesario para el emprendimiento, permitiéndole a Miguel Agüero llevar a Cádiz un caudal de 55.200 pesos fuertes ${ }^{42}$. Gracias a estas cuentas corrientes sintetizamos la evolución de los negocios de la compañía, y observamos, en tan sólo cinco años, un saldo favorable a la compañía de más de 50.000 pesos fuertes ${ }^{43}$. Teniendo en cuenta que, hasta el momento, Agüero había remitido a su sobrino unos 96.500 pesos en oro y plata; y había recibido de sus manos más de 106.000 pesos fuertes en mercaderías (lo que podríamos considerar el fruto del adelanto realizado), los 51.714 pesos líquidos (en efectivo y vales reales) que Miguel Agüero tenía de su socio eran, evidentemente, el resultado de la actividad mercantil desplegada en aquellos años. Es decir que, de acuerdo a los datos manejados, y teniendo en cuenta que las cuentas corrientes contienen todos los gastos incluidos, habría producido un $48 \%$ de ganancia.

${ }^{41}$ Cuentas de venta y otras varias producidas por mi hijo politico Miguel y Don Bartolomé de Lopetedi, MHN-U, AFA, tomo X (Cuentas).

${ }^{42}$ Demostración de la compra, inversión y premios [...] de 69.000 pesos de 128 cuartos, Cádiz, 20 de diciembre de 1800, MHN-U, AFA, tomo X (Cuentas).

${ }^{43}$ Cuentas corrientes entre Diego de Agüero y Miguel Fernández de Agüero (1796-1801), MHN-M, AA, tomo XVII y AFA, tomo X (Cuentas). 
Sin embargo, una vez más, es nuestro deber mostrar las debilidades de este dato que, principalmente, carece de un cálculo más certero de los gastos que implicaba el movimiento mercantil. Pese a que ellos, en teoría, se encuentran incluidos en las cuentas corrientes, hemos calculado dicho porcentaje sobre los montos brutos que los documentos consignan, sin tener la posibilidad de ponderar los elementos que enumeramos en el acápite anterior, y que dificultan una medición más certera de la ganancia mercantil en aquella coyuntura bélica (falta de pagos de los seguros; devaluación permanente de los vales reales adquiridos ${ }^{44}$; gastos provocados por la situación de guerra, no incluidos en las cuentas corrientes de Miguel Agüero por desconocerlos ${ }^{45}$; imposibilidad de calcular exactamente el costo de cada una de las recepciones de caudales en la península ibérica ${ }^{46}$. De hecho, también existía la posibilidad de que los deudores enviasen sus remesas de dinero a Cádiz sin pasar por Buenos Aires (como ocurrió en 1802, cuando desde Lima se remitieron 5.430 pesos fuertes a Miguel Agüero), aunque la correspondencia muestra de que sólo ocurrió excepcionalmente ${ }^{47}$.

No obstante las dificultades para acceder a un dato más exacto, pasemos a la pregunta clave: si sabemos que Agüero invirtió poco más de 350.000 pesos para la adquisición de mercancías en Cádiz, ¿cuál fue la ganancia que le produjo su venta en América? Y aunque la respuesta no puede ser definitiva (en tanto ya señalamos la imposibilidad de conocer el resultado de cada venta y el problema que implica estimar una determinada ganancia promedio, en tanto ella era aleatoria y coyuntural), existe un mecanismo que nos permite evaluar tres posibles escenarios, gracias a un documento notarial suscripto por

${ }^{44}$ El líquido de Agüero se dividía en 25.399 pesos en efectivo y 30.661 en vales reales, Miguel Agüero a Diego de Agüero, 27 de noviembre de 1797, MHN-U, AA.

${ }^{45}$ Por ejemplo, Miguel Agüero no incluyó en sus cálculos de utilidades los gastos que debió afrontar otro miembro de la compañía, Blas Antonio de Agüero (hijo de Diego y primo de Miguel), Maestre del buque de los Agüero La Medea, capturado por los ingleses y conducido a Londres, en 1804. Cuenta de gastos desde mi salida de Tavistock hasta mi partida de Londres para España inclusos los de mi viaje y otros causados durante mi estadía en aquella capital, Blas Antonio Agüero, Cádiz, 31/10/1805, en MHN-U, AA, tomo XIV.

${ }^{46}$ La mayoría de las remesas fueron tomadas en bruto, pese a que su recepción en España tenía un costo que varió a lo largo del medio siglo de comercio (el oro podía llegar a abonar hasta el $4 \frac{3}{4} \%$ del monto de la remesa $-1 \frac{1}{2}$ de Derechos reales; $1 \frac{1}{2} \%$ Consulado antiguo; $1 / 2 \%$ Consulado moderno; $1 \frac{1}{2} \%$ donativo al Rey; $1 \frac{1}{2} \%$ Consejo; $1 \frac{1}{4} \%$ flete y contado del dinero- más 20 reales por hojas utilizadas y, en caso de remitirse tejos, debía pagarse derechos al ensayador.

47 Debe tener en cuenta el lector que accedimos a los ocho cuadernos copiadores de cartas privadas de Agüero entre 1774 y 1808, a los que se suman cientos de cartas que exceden dicho período, por lo que suponemos haber accedido a una parte sustantiva de la correspondencia por él enviada a lo largo de su carrera. De allí que consideremos a esta situación como excepcional. 
Agüero, que da cuenta de los porcentajes de ganancia esperados de acuerdo a la coyuntura que atravesaran los mercados. En diciembre de 1803, al otorgarle un fiado de mercancías a un grupo de comerciantes de Jujuy y Chuquisaca, Agüero especifica las siguientes condiciones:

...si en el término de tres meses $[\ldots]$ se supiese de positivo en esta capital que
nuestra corte tuviese guerra declarada con alguna de las dos potencias de Francia
o Inglaterra, o que cualquiera de éstas nos la haya declarado, le han de satisfacer
dichos efectos con el aumento de ochenta por ciento sobre los principales que
traen de Cádiz según las facturas originales que les puso [Agüero] de manifiesto,
en cuyo caso importan los expresados efectos la cantidad de 93.619 pesos cinco y
medio reales moneda corriente... ${ }^{48}$.

Asimismo, se estipula que si «no hubiese aquí noticia contraria a la neutralidad [...] en que subsistía nuestra corte le han de satisfacer dichos efectos con el aumento de treinta y cuatro por ciento sobre los dichos principales», es decir, 69.819 pesos siete y cuartillos reales. Finalmente, el acuerdo señala que «si en el término prevenido se hubiese ajustado la paz general entre ingleses y franceses, se han de satisfacer dichos efectos con el aumento de veinticinco por ciento» (65.196 pesos 7 reales).

Como podemos ver, la tasa de ganancia que Agüero esperaba obtener de sus mercancías fiadas variaba entre un $25 \%$ y un $80 \%$, dependiendo, fundamentalmente, de la coyuntura político-militar que atravesara el imperio español. Es decir que, con las mercancías ya en América, los comerciantes se beneficiaban con el estallido de guerras que impidiesen un tráfico normal, en tanto ello provocaba escasez y permitía mayores niveles de especulación en las ventas. En síntesis, el porcentaje de ganancia podía ser, esquemáticamente, de un $25 \%$ en tiempos de paz, de un $34 \%$, en períodos de guerra sin participación de España, y de un $80 \%$, si ella intervenía directamente en el enfrentamiento entre las dos principales potencias europeas.

Es decir que, atendiendo a que España protagonizó buena parte de los enfrentamientos bélicos, es probable que, en el corto plazo, los Agüero se hayan beneficiado notablemente de las numerosas mercancías que habían logrado importar desde Cádiz en aquellos turbulentos años, aunque se ha comprobado que las guerras y revoluciones fueron un arma de doble filo para los comerciantes coloniales.

48 Protocolos Notariales, Registro 4, 1803, AGN-A. 


\section{La ganancia en la exportación de frutos americanos}

Pese a que el grueso del comercio atlántico de Agüero se caracterizó por la importación de géneros textiles y la exportación de metales preciosos, tal como resume el gráfico 4 , también debe señalarse que la venta de productos americanos en la península ibérica también les otorgó ciertos márgenes de ganancia ${ }^{49}$.

Como es evidente, la exportación de caudales predomina ampliamente por sobre la de frutos, con 114 navíos que trasladaron oro y plata, contra 23 que hicieron lo propio con producciones americanas. La diferencia entre ambas mercancías se acrecienta en tanto lo que distingue a los metales preciosos es su capacidad para guardar una mayor cantidad de valor en pequeñas proporciones, a diferencia del resto de los bienes, de mayor volumen y menor

Gráfico 4. Contenido de las exportaciones de Diego de Agüero (1770-1816)

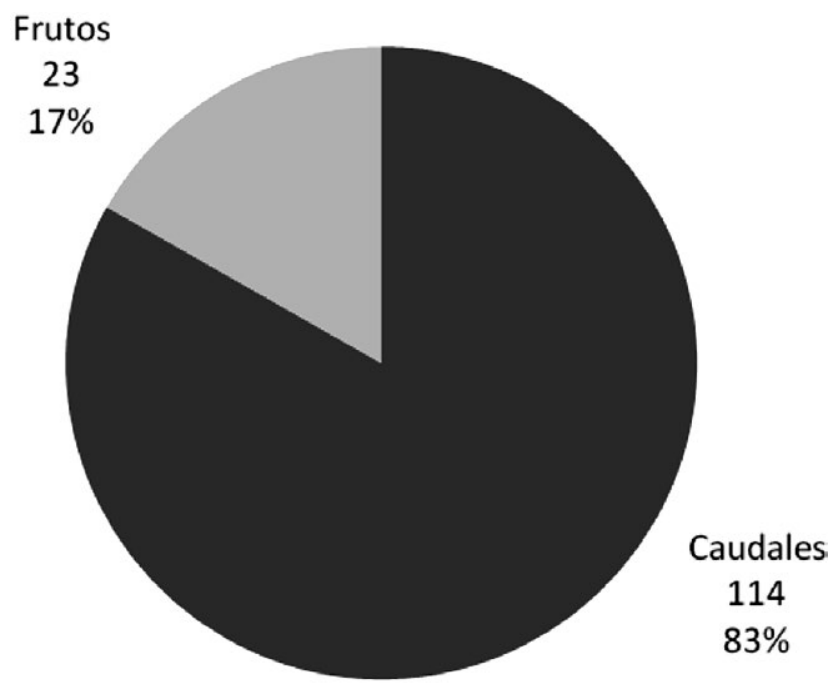

En cantidad de navíos.

Fuentes: ídem gráfico 1.

49 La única mercancía importada que no provenía del circuito de Cádiz eran los esclavos, los que Agüero adquiría en Buenos Aires, generalmente requerido por comerciantes del interior. De todas maneras, no se especializó en dicho tráfico, dado que tan sólo hemos podido comprobar la compra y venta de 23 esclavos, a un precio promedio de 300 pesos corrientes, produciendo un volumen de tan sólo 6.900 pesos corrientes. Ver Schlez, 2016a. 
valor relativo. Más allá de esto, no debemos menospreciar la importancia de la exportación de frutos a la hora de ponderar la ganancia.

Durante el grueso de su actuación mercantil, entre 1770 y 1796, Agüero sólo exportó frutos por cuenta de terceros. En ese caso, las comisiones podían ser menores a las cobradas por el tráfico de géneros y caudales: en septiembre de 1779, por ejemplo, Agüero le cobra a Salvador de Trucios, por el envío de 20 cajones de cascarilla a Cádiz, una comisión de tan sólo el $2 \%$, que le redituó 22 pesos corrientes 4 reales, para una mercancía de un valor aproximado a los $1100 \operatorname{pesos}^{50}$. No obstante, el comercio de frutos expresa la misma irregularidad de comisiones a la que ya nos referimos, dado que también hemos comprobado ventas de cobre en Buenos Aires en que Agüero cobró a su socio el 4\% (en 1781, la venta de 154 barras de cobre a 4649 pesos corrientes le habrían redituado unos 186 pesos corrientes).

Sin embargo, la situación comenzó a modificarse a partir del inicio de la crisis del comercio colonial, con el estallido de la guerra anglo-española de 1796. En aquella coyuntura, el bloqueo de Cádiz por la flota inglesa obligó a los Agüero a reformular nuevamente sus rutas comerciales (uniendo Cádiz y el Río de la Plata a través de Río de Janeiro y Lisboa), sus vínculos y contactos (incorporando a casas, comerciantes y aseguradoras de Portugal y Brasil), y el contenido de su giro (atentos a los peligros del transporte de caudales y a alteraciones en la demanda de sus nuevos socios). Fue así que, acorralados por las circunstancias, comenzaron a desarrollar un incipiente tráfico de frutos por cuenta propia, a través de la simulación de dos buques bajo bandera portuguesa, por medio de la vía de Río de Janeiro y Lisboa, y en sociedad con comerciantes criollos (Diego de Agüero, 35\%; Miguel Fernández de Agüero, 22\%; Joaquín de Arana, 16\%; Francisco de la Peña Fernández, 16\%; y Carlos Somoza, 11\%), una casa comercial gaditana (Torre y Hermanos, propietaria del buque) y una portuguesa-británica (Gould, Kirwan).

Lamentablemente, no contamos con el detalle exacto de los volúmenes y mercancías, dado que no se han conservado los registros de su salida de Montevideo, ni tampoco hemos hallado su entrada en Cádiz, adonde llegaron finalmente desde Ayamonte. No obstante, las cuentas de venta de Miguel Agüero, enviadas a su socio desde la península ibérica, nos informan de lo provechoso de la venta de frutos en aquellos belicosos años: en 1803, vendieron en Cádiz, en una sola operación, 11.134 cueros de novillo; 2142 cueros de caballo y 25 libras de planchas y puntas de astas a 344.093 reales plata (43.011,5/8 pesos de 128 cuartos o 34.462 pesos de América), con gastos

${ }^{50}$ Cuenta de venta de Diego de Agüero a Salvador de Trucios, 9/1779, Sala VII, AA, leg. 761, AGN-A, AA. 
ya descontados ${ }^{51}$. Naturalmente, no estamos frente al monto de la ganancia neta (de allí debían descontarse los gastos rioplatenses, fundamentalmente su costo de compra, su almacenamiento en barracas, su traslado en lancha desde Buenos Aires a Montevideo, su carga en los buques y el pago de los derechos correspondientes -2.123 pesos corrientes 7 reales del $4 \%$ de alcabala y ramo municipal de guerra-), aunque es evidente que el volumen de la venta de frutos comienza a acercarse al de los géneros. Esta tendencia se acrecentó en lo sucesivo: en 1805, Bartolomé de Lopetedi vendió en Cádiz, por cuenta de Agüero, 10.195 cueros al pelo, los que produjeron una ganancia neta de 28.012 pesos fuertes (sin contarse comisión de Lopetedi). Posteriormente, el 15 de diciembre de 1807, el mismo consignatario vendió 6930 cueros de caballo, los que resultaron, gastos descontados, en 7564 pesos fuertes. Datos que señalan la revalorización de los frutos en el giro de los Agüero, los que aportaron un volumen mínimo de 70.000 pesos fuertes (provenientes de tan sólo tres operaciones), aunque no llegaron a modificar la estructura tradicional de su giro.

\section{ORIGEN Y VOLUMEN DEL PATRIMONIO}

Al finalizar sus cuentas, los comerciantes coloniales aclaraban, antes del resultado final, que se trataba de un cálculo "salvo yerro u omisión». Los ingleses tenían la misma costumbre, apelando al concepto errors excepted. Tomaremos entonces esta tradición, antes de sintetizar los resultados de nuestro análisis de la ganancia mercantil de Diego de Agüero en el cuadro:

El mismo resume los datos presentados hasta el momento y nos permite confirmar una serie de elementos ya evidentes. En primer lugar, vemos que la ganancia fruto de su actuación como comisionista, tanto en las importaciones de géneros, como en las exportaciones de caudales, le reditúa unos 86.000 pesos. A continuación, se muestra que su actuación como comerciantes por cuenta propia, en sus dos fases (Carranza / Fernández de Agüero), le permitió acumular el grueso de sus riquezas, superando los 415.000 pesos $^{52}$. Muy lejos

${ }^{51}$ Cuenta de venta, gastos y líquido producto de 11.134 cueros al pelo de toro y novillo; 21 pacas con 2142 cueros de caballo; y 25 libras de planchas y puntas de astas, que mi suegro Don Diego de Agüero cargó en Montevideo de cuenta y riesgo de ambos en la Fragata Correo de Lisboa, su Maestre Don Pablo Columbo, según factura de 27 de noviembre de 1802, Miguel Fernández de Agüero, Cádiz, 18 de abril de 1803, MHN-U, AFA, tomo X (Cuentas).

${ }_{52}$ Mientras que la ganancia de la compañía Agüero-Carranza fue calculada a partir de la documentación específica de cada una de las operaciones, la que corresponde a la compañía Agüero-Fernández de Agüero se trata una estimación mínima, a partir del conocimiento del 


\section{Cuadro 6. Niveles de ACUMUlación y PORCEnTAJes de GANANCia DE Diego De AgÜERo (1767-1820)}

\begin{tabular}{|l|c|c|}
\hline Actividad & $\begin{array}{c}\text { Volumen } \\
\text { Monetario }\end{array}$ & $\begin{array}{c}\text { Ganancia } \\
\text { estimada }\end{array}$ \\
\hline Importaciones por comisión & 526.762 & 36.873 \\
\hline Exportaciones de caudales por comisión & 723.634 & 50.934 \\
\hline Sociedad Diego de Agüero-Tomás de Carranza & 32.436 & 3.383 \\
\hline Importación sociedad Diego y Miguel Agüero & 344.107 & 412.928 \\
\hline Exportación de caudales sociedad Agüero & 318.758 & - \\
\hline Exportación de frutos por comisión y cuenta propia & 70.000 & 7.000 \\
\hline Total & - & 516.818 \\
\hline
\end{tabular}

En pesos fuertes de América.

Fuente: ídem gráfico 1.

del aporte realizado por la exportación de frutos, la que también expresa un nivel mínimo.

Este balance nos lleva a concluir, entonces, que los Agüero pertenecieron a la fracción más poderosa de los comerciantes tardo-coloniales rioplatenses. Como se ha probado a través del análisis de las testamentarias, nos referimos a individuos que acumularon ganancias que oscilaron entre los 50.000 y los 400.000 pesos $^{53}$. De todas maneras, se observa un proceso de acumulación de riquezas que, no obstante de finalizar con un signo positivo, parece describir una parábola que decrece a principios del siglo XIX. Mientras que Agüero inicia su carrera con una riqueza estimada en los 10.000 pesos (declarados al momento de su matrimonio, en 1769), hemos visto que durante el período

costo de la totalidad de géneros que importaron desde Cádiz. Para obtener ese monto, que consideramos mínimo, hemos sumado al gasto en la compra de mercancías $20 \%$, como aproximación a la ganancia estimada de la venta de esa masa de géneros y efectos. Mecanismo que repetimos con la estimación de la ganancia de los frutos.

53 Según Socolow (1991: 213), entre los principales patrimonios rioplatenses se encuentran los de Francisco Segurola (395.077 pesos), Francisco de Tellechea (308.399 pesos), Domingo de Basavilbaso (222.896 pesos), José santos Inchaurregui (206.597 pesos), Vicente de Azcuénaga (198.449 pesos) y Juan José Lezica (161.441 pesos) . De hecho, dichas fortunas se componía de la totalidad de riquezas que poseía un individuo, bajo sus diferentes formas (metales preciosos, inmuebles, mobiliario, esclavos, mercaderías u deudas a favor y en contra, además de otros ítems dependiendo el caso), y no solamente de la ganancia mercantil obtenida. Lamentablemente, la testamentaria de Agüero no sintetiza sus riquezas al morir. Sucesión de Diego de Agüero, AGN-A, Tribunales Sucesiones, 3508. 
de auge de su giro mercantil, entre 1785 y 1809, su volumen comercial le permitió alcanzar niveles de acumulación que superaron los 500.000 pesos (en efectivo y mercancías). No obstante, en 1812, con motivo de defenderse del ataque del gobierno revolucionario, Agüero declaró en juicio que poseía 33.475 pesos en plata y 10.019 pesos 4 reales en doblones de a 16 pesos fuertes de su propiedad particular ${ }^{54}$. Si bien una declaración en condiciones de ser expropiado por un gobierno revolucionario puede resultar de dudosa valía para medir sus riquezas, los 43.494 pesos en efectivo no parecen acercarse a las riquezas de los mejores tiempos. La Revolución de Mayo y la crisis general del comercio colonial, parecen haber influido negativamente en el desarrollo de su comercio, el que tiene un abrupto final pocos años después de iniciadas las guerras revolucionarias sudamericanas.

\section{Conclusiones}

El artículo muestra, en primer lugar, que el origen de las ganancias que Diego de Agüero obtuvo provenía, fundamentalmente, de su comercio, y no de otro tipo de actividades que, como ha probado la historiografía, desplegaron otros sectores mercantiles (seguros, inversiones productivas, adquisición de haciendas, etc.). Es decir que, pese al desarrollo de otro tipo de negocios (otorgamiento de crédito, actividades inmobiliarias), el grueso de sus riquezas tenía su origen en su capacidad para sustraer una parte del valor en circulación, sin vinculación alguna con el mundo de la producción.

En segundo lugar, hemos medido, de la manera más exacta posible, el patrimonio obtenido por Diego de Agüero a lo largo de su carrera, lo que nos mostró que estamos frente a un sujeto que logró acumular una masa notable de riquezas, que lo coloca entre los sectores más ricos de todo el Virreinato del Río de la Plata. De hecho, no analizamos más pormenorizadamente sus (posibles) actividades de contrabando, las que resultarían, probablemente, en un volumen aún mayor de riquezas obtenidas. Más allá de eso, el comprobar que Agüero fue uno de los principales comerciantes porteños resulta un elemento de interés a la hora de evaluar el peso material concreto de la fuerza social contrarrevolucionaria (de la que fue uno de sus principales dirigentes), que se opuso al proceso iniciado con las invasiones inglesas al Río de la Plata ${ }^{55}$.

Por su parte, es evidente que la actividad empresarial de Agüero fue ganando en complejidad con el tiempo, en tanto se observa que pasó de comi-

\footnotetext{
${ }^{54}$ Pertenencias Extrañas, AGN-A, Sala IX, Expedientes, tomo 7, $\mathrm{n}^{\circ}$ 26, 15-2-15.

${ }^{55}$ Harari, 2009.
} 
sionista a cuentapropista, de solicitar créditos al autofinanciamiento, y de la tercerización del transporte a la adquisición de buques. Respecto de esto, es probable que la reducción de sus costes de transacción le posibilitara acrecentar sus márgenes de ganancia, al eliminar de sus negocios a aquellos servicios que, en sus primeras actividades, se apoderaron del grueso de su beneficio. Es decir que estamos frente a un sujeto que desplegó una estrategia efectiva para el desarrollo de sus negocios, siempre que la coyuntura, y su propio lugar en la estructura social, se lo permitieron.

Finalmente, debemos concluir que, en este caso, no se observa la existencia de una tasa de ganancia, en el sentido capitalista del término. Por el contrario, se prueba que Agüero obtuvo una enorme variedad de porcentajes de lucro a lo largo de su carrera, lo que implica un avance importante en la definición de la naturaleza social de los comerciantes que, como él, se beneficiaron del monopolio español. En este sentido, la divergencia de precios y márgenes de lucro muestra que estamos frente a un tipo específico de burguesía mercantil, que no obtenía una tasa regulada por su función de distribución, sino que se reproducía gracias al despliegue de diferentes tipos de usuras, acopios, monopolios, especulaciones, escasez y desequilibrios entre mercados lejanos, desconocidos y restringidos. Es decir que dicha apropiación de riquezas sólo fue posible gracias a la existencia de un sistema social específico, en donde aún predominaba el privilegio político otorgado por la Monarquía para comerciar, lo que actuaba como mecanismo de defensa frente al avance de mercaderes y productos más competitivos.

\section{BiBLIOGRAFÍA}

Álvarez, Juan, Temas de Historia Económica Argentina, El Ateneo, Buenos Aires, 1929.

Astarita, Carlos, Desarrollo desigual en los origenes del capitalismo. El intercambio asimétrico en la primera Transición del feudalismo al capitalismo. Mercado feudal y mercado protocapitalista. Castilla, siglos XIII a XVI, Buenos Aires, Facultad de Filosofía y Letras, Universidad de Buenos Aires / tesis 11, 1992.

Belgrano, Manuel, "Autobiografía del General Don Manuel Belgrano", Senado de la Nación, Biblioteca de Mayo. Autobiografías, vol. II, Buenos Aires, Senado de la Nación, 1960.

Bernal, Antonio-Miguel, La financiación de la Carrera de Indias (1492-1824). Dinero y crédito en el comercio colonial español con América, Sevilla, Consorcio Urbanístico del Pasillo Verde/Fundación El Monte, 1992. 
Brading, David, Mineros y comerciantes en el México Borbónico (1763-1810), México, FCE, 1975.

Carmagnani, Marcello, "Formación de un mercado exclusivo y el papel de los mercaderes: la región de Santiago de Chile (1559-1600)", Jahrbuch fur Geschichte von Staat, Wirtschaft und Gessellschaft Lateinamerikas, 12 (Köln, 1975): 104-133.

Chiaramonte, José Carlos, Formas de sociedad y economía hispanoamericana, México, Grijalbo, 1984.

Crespo Solana, Ana (coord.), Comunidades transnacionales: colonias de mercaderes extranjeros en el Mundo Atlántico (1500-1830), Madrid, Ediciones Doce Calles, 2010.

Dalla Corte, Gabriela, Vida i mort d' una aventura al Riu de la Plata. Jaime Alsina y Verjés, 1770-1836, Barcelona, Publicacions de L'Abadia de Montserrat, 2000.

Fisher, John, "Fuentes para el estudio del comercio entre España y América en el último cuarto del siglo XVIII: los registros del Archivo General de Indias", Archivo Hispalense, 68/207-208 (Sevilla, 1985): 287-302.

Garavaglia, José Carlos, Mercado interno y economía colonial, México, Grijalbo, 1983.

García-Baquero González, Antonio, Cádiz y el Atlántico, 1717-1778: el comercio colonial español bajo el monopolio gaditano, Sevilla, EEHA/CSIC, 1976.

García-Baquero González, Antonio, Comercio y burguesía mercantil en el Cádiz de la Carrera de Indias, Cádiz, Diputación Provincial de Cádiz, 1989.

García-Baquero, Antonio, La Carrera de Indias: suma de la Contratación y océano de negocios, Sevilla, Algaida/Expo'92, 1992.

Gelman, Jorge, "El gran comerciante y el sentido de la circulación monetaria en el Río de la Plata colonial tardío", Revista de Historia Económica, 5/3 (Madrid, 1987): 485-507.

Gelman, Jorge, "Sobre el carácter del comercio colonial y los patrones de inversión de un gran comerciante en el Rio de la Plata del siglo XVIII", Boletín del Instituto de Historia Argentina y americana "Dr. Emilio Ravignani”, Tercera Serie, 1 (Buenos Aires, 1989): 51-69.

Gelman, Jorge, "Venta al contado, venta a crédito y crédito monetario en América colonial: Acerca de un gran comerciante del virreinato del Río de la Plata", Jahrbuch fur Geschichte von Staat Wirtschaft und Gesellschaft Lateinamerikas, 27 (Köln, 1990): 101-126.

Gelman, Jorge, De mercachifle a gran comerciante. Los caminos del ascenso en el Rio de la Plata colonial, España, UNIARA, 1996.

Greenow, Linda, Credit and socioeconomic change in colonial Mexico. Loans and Mortgages in Guadalajara, 1720-1820, USA, Westview Press, 1983. 
Gutiérrez Lorenzo, María Pilar, "Una quiebra comercial gaditana a fínales del siglo XVIII: la compañía Blasco y Guerra”, Estudios de Historia Social y Económica de América, 3-4 (Madrid, 1988): 111-122.

Harari, Fabián, Hacendados en armas. El cuerpo de Patricios, de las Invasiones Inglesas a la Revolución de Mayo (1806-1810), Buenos Aires, Ediciones ryr, 2009.

Herrera Vegas, Diego Jorge y Jáuregui Rueda, Carlos, Familias argentinas, Buenos Aires, Callao, 1823. (Buenos Aires, Pearson, 2003).

Herrero, María Dolores, El mundo de los negocios de Indias, Madrid, CSIC/Universidad de Sevilla/Diputación de Sevilla, 2013.

Jumar, Fernando, Le commerce atlantique au Río de la Plata, 1680-1778, 2 vols., Villenueve d'Ascq (Francia), Presses Universitaires du Septentrión, 2002.

Jumar, Fernando, "Los circuitos mercantiles revelados por los registros de aduana de Buenos Aires, 1779-1783", II Congreso Latinoamericano de Historia Económica, México, 3 al 5 de febrero, 2010.

Jumar, Fernando, "Comerciantes en Río de la Plata pre-virreinal. El caso de Domingo de Basavilbaso", Anuario del Instituto de Historia Argentina, 11 (La Plata, 2011): 205-240.

Kicza, John, Empresarios coloniales. Familias y negocios en la ciudad de México durante los borbones, México, FCE, 1986.

Kriedte, Peter, Feudalismo tardio y capital mercantil, Barcelona, Crítica, 1987.

Laclau, E., Cardoso, C. F. S., Ciafardini, H., Garavaglia, J. C. y Sempat, Carlos, Modos de producción en América Latina, México, Siglo XXI, 1989.

Laviana Cuetos, María Luisa, "La organización de la Carrera de Indias, o la obsesión del monopolio", El comercio marítimo ultramarino. Cuadernos Monográficos del Instituto de Historia Naval, 52 (Madrid, 2006): 19-35.

Lobato, I. y Oliva, J. M., El sistema comercial español en la economía mundial (siglos XVII-XVIII). Homenaje a Jesús Aguado de los Reyes, Huelva, Universidad de Huelva, 2013.

Martínez Shaw, Carlos, Cataluña en la Carrera de Indias, 1680-1756, Barcelona, Crítica, 1981.

Marx, Karl, El Capital, 3 vols., Buenos Aires, FCE, 2000.

Moutoukias, Zacarías, "Reseaux personnels et autorité coloniale: les négociants de Buenos Aires au XVIII siècle”, Annales E.S.C., 4-5 (París, 1992): 889-915.

Newland, Carlos, "Globalización en el Imperio español: precios y comercio entre 1661 y 1810”, 2000 meeting of the Latin American Studies Association, Miami, Hyatt Regency, March 2000: 16-18. 
Otte, E., "Mercaderes burgaleses en los inicios del comercio con México", Historia Mexicana, 18 (México, 1968): 108-144.

Rodríguez Vicente, Encarnación, "La contabilidad privada como fuente histórica", Anuario de Estudios Americanos, 32 (Sevilla, 1975): 303-327.

Romano, Ruggiero, Una Economía colonial, Chile en el siglo XVIII, Buenos Aires, Eudeba, 1965.

Ruiz Rivera, Julián, "Rasgos de modernidad en la estrategia comercial de los Ustáriz, 1766-1773, Temas Americanistas, 3 (Sevilla, 1983): 32-46.

Schlez, Mariano, "Diego de Agüero y los fundamentos económicos de la clase dominante en el Río de la Plata tardo colonial (1770-1810)", Antonio García de León, Luis Jáuregui y José Antonio Serrano Ortega, (eds.), La Corona en llamas. Cuestiones económicas y sociales en las independencias iberoamericanas, Castellón, Universitat Jaume I, 2010: 27-60.

Schlez, Mariano, "Enemigos declarados de nuestro sistema. La acción política contrarrevolucionaria de Diego de Agüero y Miguel Fernández de Agüero (1770-1816)", Anuario del Instituto de Historia Argentina, 11 (La Plata, 2011): 257-296.

Schlez, Mariano, "Antes del fin. Los comerciantes monopolistas frente a la crisis y la Revolución (Montevideo, 1789-1820)", Tiempos de América, 19 (Castellón, 2012): 17-35.

Schlez, Mariano, "Comercio y sociedad en el Virreinato del Río de la Plata (17701820)", Begoña Cava Mesa (coord.), América en la Memoria: Conmemoraciones y Reencuentros, vol. II, Bilbao, Asociación Española de Americanistas/Universidad de Deusto, 2013: 427-446.

Schlez, Mariano, "¿Esclavistas versus monopolistas? Las disputas en torno al tráfico de esclavos en el virreinato rioplatense (1780-1810)", Boletín Americanista, 72 (Barcelona, 2016a): 133-154.

Schlez, Mariano, "El comercio de un monopolista. Volumen, contenido y sentido de la circulación, según un estudio de caso (Río de la Plata, 1770-1820)", Anuario de Estudios Americanos, 73-1 (Sevilla, 2016b): 163-198.

Schmidt, Peer, "Los vales reales y la desamortización de Carlos IV en España (17981808). Una perspectiva desde Cádiz, Sevilla y el Reino de Sevilla", Memorias del Segundo Congreso de Historia Económica. Entre la Economía y la Historia, México, AMHE/UAM, 2004.

Silva, Hernán A. (dir.), Historia económica del Cono Sur de América. Argentina, Bolivia, Brasil, Chile, Paraguay y Uruguay. La era de las revoluciones y la Independencia, México, Instituto Panamericano de Geografía e Historia, 2010.

Socolow, Susan, "Economic Activities of the Porteño Merchants: The Viceregal Period", The Hispanic American Historical Review, 55/1 (North Carolina, Feb. 1975): 1-24. 
Socolow, Susan, Los mercaderes del Buenos Aires virreinal: familia y comercio, Buenos Aires, De la Flor, 1991.

Suárez Argüello, Clara, "Las compañías comerciales en la Nueva España a fines del siglo XVIII: El caso de la compañía de Juan José de Oteyza y Vicente Garviso (1792-1796)", Estudios de Historia Novohispana, 28/28 (México, 2003): 103-139.

Tándeter, Enrique y Wachtel, Nathan, "El papel de la moneda macuquina en la circulación monetaria Rioplatense", Cuadernos de Numismática, 14 (Buenos Aires, 1975): 1-11.

Tortella, Gabriel, "Sobre los orígenes del seguro en España", X Congreso Internacional de la Asociación Española de Historia Económica, AEHE, Carmona (Sevilla), Universidad Pablo de Olavide, 8-10 de Septiembre, 2011: 1-18.

Vázquez Cienfuegos, Sigfrido y Santamaría García, Antonio, “Cuba económica en tiempos de las independencias Americanas. La hacienda y la consolidación de los vales reales en comparación con el caso de México", Revista de Historia Económica, 30/1 (Madrid, 2012): 91-124.

Vila Vilar, Enriqueta, "Los mercaderes sevillanos y el destino de la plata de Indias", Minervae baeticae. Boletín de la Real academia Sevillana de Buenas Letras, 29 (Sevilla, 2001): 85-101.

Vilar, Pierre, Cataluña en la España moderna. La formación del capital comercial, vol. 3, Barcelona, Crítica, 1988.

Fecha de recepción: 29 de agosto de 2014.

Fecha de envío de las modificaciones: 19 de noviembre de 2014.

Fecha de aceptación: 20 de noviembre de 2014. 


\section{Measuring commercial profit in the Rio de la Plata colony: the case of Diego de Agüero and Company (Rio de la Plata, 1770- 1820)}

The article reconstructs the commercial activities of the company of one of the leading traders of the Viceroyalty of Rio de la Plata, the Spaniard Diego de Agüero, throughout its commercial operations (1770-1820), in order to measure and analyse the origin of its profits and gauge the magnitude of its legacy. To do so, it resorts to serial documentation (ship's records and annual registers) and private papers (correspondence, accounting books, etc.) from repositories in Argentina, Uruguay, Brazil, Bolivia and Spain. By so doing, it shows the absence of a rate of profit in the contemporary sense of the term for the case in question, and the huge disparity in results in its business operations, which could only be conducted thanks to the existence of a specific social system, which resisted the advance of competition through non-economic mechanisms.

KEY WORDS: Spanish Empire; Colonial Trade; Merchants; Rate of profit. 